\title{
RENOVACIÓN URBANA Y ROL MUNICIPAL PRO-EMPRESARIAL EN EL MANEJO DE INSTRUMENTOS DE PLANIFICACIÓN TERRITORIAL: SANTIAGO DE CHILE, 1990-2012.
}

\section{Resumen}

Desde la década de 1990 las comunas del centro y pericentro del Gran Santiago vienen experimentando un proceso intensivo de renovación urbana residencial privada con tipologías de edificios de departamentos en altura. El presente artículo examina el rol que cumplen los municipios en dicho proceso, en circunstancias de predominancia de esquemas de gestión urbana pro-empresarial. Se analizan distintos modos por los cuales los municipios de Santiago, Ñuñoa, Recoleta e Independencia, incorporan ajustes normativos en sus ordenanzas locales, a fin de atraer a los agentes inmobiliarios privados. Estos tipos de ajustes normativos han sido clasificados como permisivos, flexibles y/o dirigidos, con el fin de comprender las específicas modalidades en que los municipios logran adecuarse a las lógicas de producción inmobiliaria.

Palabras clave: renovación urbana, pericentro, urbanismo pro-empresarial, ajustes normativos, renta de suelo.

\section{Resumen}

Since 1990 s central district and inner-city of Gran Santiago are undergoing a intensive process of residential urban renewal, with apartment building typologies in height. This article examines the role played by municipalities in this process, in terms of predominance of urban management schemes pro-empreneurialism. It discusses various ways in which the municipalities of Santiago, Nuñoa, Recoleta and Independencia, incorporate policy adjustments in their Ordenanzas Locales in order to attract real estate companies. These types of policy adjustments have been classified as permissive, flexible and / or directed, in order to understand the specific ways in which municipalities able to adapt to the logic of real estate production.

Keywords: urban renewal, inner-city, urban entrepreneurialism, policy adjustments, ground rent.

\section{Introducción}

Iniciada la década de 1990, se comienza a implementar en el Gran Santiago una estrategia pública de renovación urbana con perspectiva de recuperar espacios de 
alta centralidad y revertir las tasas de despoblamiento que venían registrándose desde las tres décadas anteriores. Al despoblamiento se sumó un continuado proceso de deterioro de la materia construida residencial con una notable capacidad ociosa de la infraestructura pública y equipamiento urbano que se disponía en las áreas centrales, donde se estimó, mediante un estudio en 1987, que los costos sociales de la expansión urbana eran cerca de 16 veces mayores a los costos de redesarrollar las áreas centrales ${ }^{7}$.

Frente a esta situación, lo que se hizo fue impulsar una estratégica pública de renovación urbana de Santiago que ha constado de las siguientes intervenciones de parte de gobiernos central y municipales: a) implementación de agencias privadomunicipales para atraer y anclar la actividad inmobiliaria al centro y pericentro; b) aplicación de un Subsidio de Renovación Urbana para la adquisición de viviendas económicas (inferiores a $140 \mathrm{~m}^{2}$ ) en un área definida como Zona de Renovación Urbana; y c) modificación/actualización de los Instrumentos de Planificación Territorial (IPT) para posibilitar edificaciones más intensivas en suelo, y redistribuyendo complementariamente otros usos del suelo funcional a la densificación habitacional. Como resultado se obtiene que, desde 2007 en adelante, el volumen construido y de unidades habitacionales producidas por el modelo privado de renovación urbana en altura en comunas centrales y pericentrales del Área Metropolitana del Gran Santiago (AMGS) es mayor que el de la construcción de casas unifamiliares en la periferia. Entre 1990 y 2008, la participación en el mercado residencial del pericentro ${ }^{8}$ de esta ciudad se incrementó dramáticamente desde un $7,5 \%$ hasta un $44 \%$, mientras que la periferia decreció a menos de la mitad, de un $81 \%$ a un $38,5 \%$.

En este periodo se revela una importante reestructuración de las áreas centrales con impacto a escala metropolitana; cuestión para nada exclusiva del Gran Santiago, puesto que corresponde a un proceso bastante generalizado de recuperación de la centralidad urbana en distintas ciudades latinoamericanas de las últimas dos décadas (Herzer, 2008). Siendo diversas las experiencias de reestructuración central de las ciudades de la región latinoamericana, es posible reconocer que las estrategias públicas pro-renovación intensiva generalmente operan mediante instrumentos de promoción que las administraciones locales urbanas utilizan como medios para consolidar la expansión del proceso de mercantilización del espacio urbano (Herzer, 2008; López Morales, 2011; Janoschka, Sequera y Salinas, 2013).

Para el caso chileno, la renovación urbana de áreas centrales responde al carácter subsidiario del Estado, pero también con componentes importantes de lo que se

\footnotetext{
7 Véase el informe "Imperativo de la Recuperación Urbana: Algunos Costos de la Expansión" publicado en 1987 por la Corporación para el Desarrollo de Santiago.

${ }^{8}$ Comuna de Santiago Centro más 10 comunas adyacentes.
} 
puede denominar como Urbanismo Pro-empresarial. Éste se caracteriza por instalar marcos institucionales para la competitividad urbana municipal, donde los gobiernos locales estimulan, con recursos corrientes propios o provenientes del gobierno central, la atracción de capital privado, fragmentando y flexibilizando las normativas urbanísticas locales para lograr ofertar suelo público. Por su parte, la aparición de alianzas público-privadas en la toma de decisiones sobre desarrollo urbano (como la CORDESAN), sumado a la escasa participación del gobierno central y regional en el desarrollo urbano de las áreas centrales, que se ha remitido a la propuesta de acotados proyectos detonantes que no han sido efectivamente implementados (como proyectos en Cerrillos, Anillo Intermedio, Mapocho-La Chimba), hace atingente hablar de una gestión pro-empresarialista de la renovación urbana en el Gran Santiago (López Morales, Gasic, Meza, 2012; Vicuña, 2013; López Morales, 2013b).

Es particularmente interesante observar el rol que tienen los municipios en este marco institucional de operaciones públicas pro-empresarialistas. Como ha venido sosteniendo López Morales (2011), el modelo de renovación urbana en Chile compele a los municipios a insertarse en la lógica de competitividad urbana local, ejecutando acciones específicas para aumentar las rentas potenciales que pueden extraer los desarrolladores inmobiliarios por unidad de suelo comprado, estimulando el mercado fundamentalmente a través del manejo municipal de los instrumentos de planificación territorial (IPT).

Precisamente, lo que se pretende en este artículo es ilustrar las diferentes formas en que los municipios pericentrales del Gran Santiago han intervenido sus normativas urbanísticas locales, desplegando una batería de modificaciones a sus IPT's, a fin de ajustarlos a los requerimientos del desarrollo inmobiliario en altura y las pretensiones de capturar renta urbana de parte de los mismos productores. En particular, se han observado y sistematizado "ajustes regulatorios" de seis municipios peri-centrales de Santiago ${ }^{9}$, produciendo categorías de análisis novedosas y útiles para la comprensión del rol de los gobiernos locales en la promoción de la renovación urbana residencial privada. Se han estudiado los municipios de Santiago, Ñuñoa, Recoleta, Independencia, Quinta Normal y Macul (Ver en Figura 1). Sin embargo, para efectos prácticos, en este trabajo se exponen resultados de los cuatro primeros casos.

En lo que sigue: 1) se teoriza sobre el concepto de Urbanismo Pro-Empresarial (UPE) para analizar el rol de los municipios en el proceso de renovación urbana; 2) se exponen los principales aspectos metodológicos; 3) se presenta la producción categorial de los distintos tipos de "ajustes regulatorios" estudiados; 4) se analiza y

\footnotetext{
${ }^{9}$ Estos municipios han sido seleccionados según criterios del Proyecto Fondecyt-11100337 dirigido por el Dr. Ernesto López Morales. Importante cantidad de datos del presente artículo han sido suministrados por dicho proyecto.
} 
ejemplifican casos de las cuatro comunas mencionadas, realizando estimaciones de rentabilidad inmobiliaria con y sin aplicación de los respectivos ajustes. Con base en dichos resultados, se discute y sintetizan los principales aportes de la investigación a los estudios urbanos y municipales.

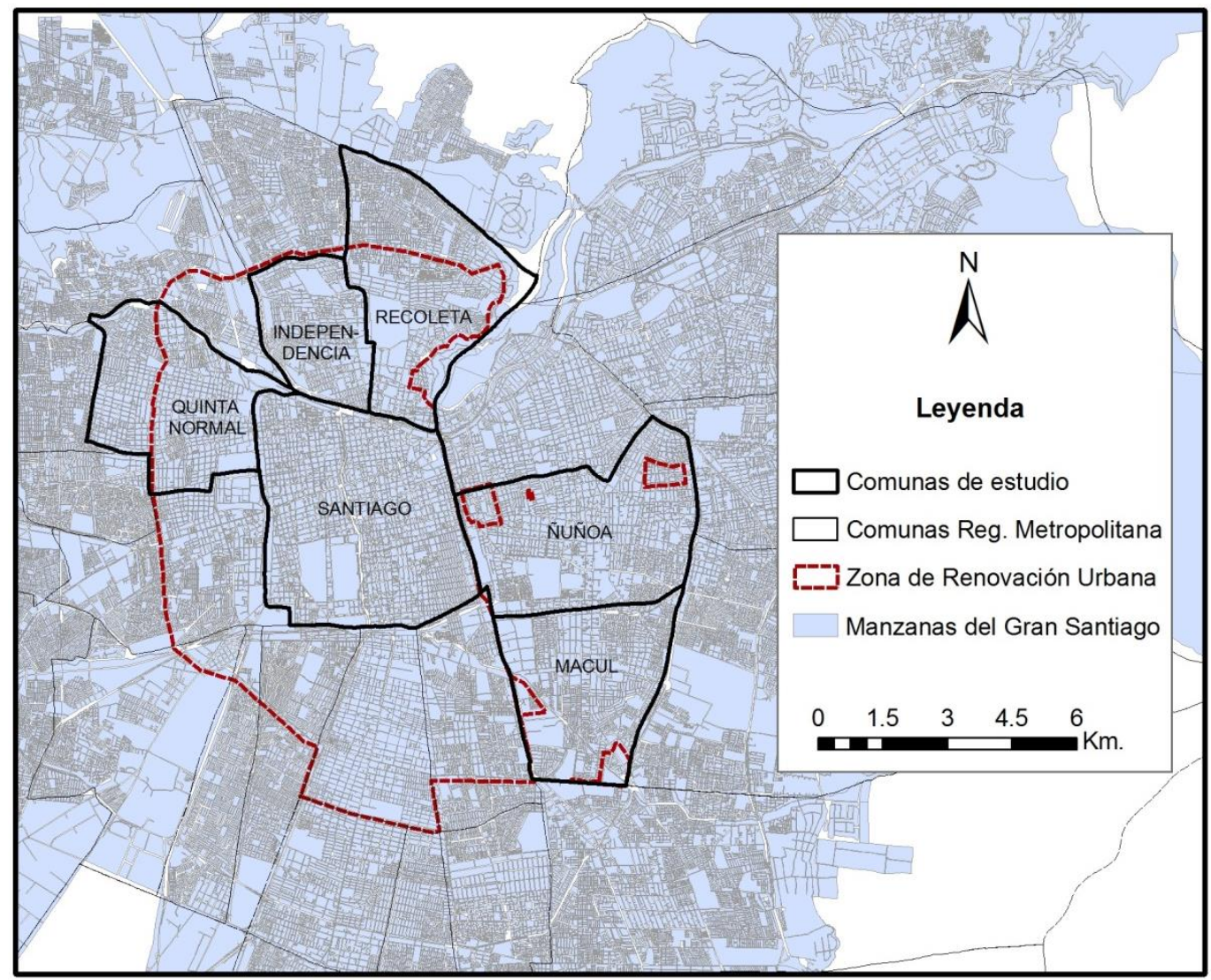

Figura 1. Mapa de comunas peri-centrales estudiadas en el Gran Santiago. Fuente: elaboración propia.

\section{Ajustes en la regulación del suelo urbano. Un acercamiento al carácter pro- empresarialista de la gestión urbana municipal.}

En términos generales, el esquema del pro-empresarialismo urbano expuesto inicialmente por David Harvey (1989) plantea que el devenir neoliberal del Estado keynesiano no implica una disminución de la intervención de éste en el desarrollo de la ciudad sino una nueva forma de gobernabilidad urbana adecuada al funcionamiento de un régimen de acumulación flexible basado en una mayor volatilidad del capital. El comportamiento pro-empresarialista de los gobiernos urbanos se basa, precisamente, en la competencia que establecen las ciudades por la atracción del capital altamente móvil, lo que requiere muchas veces una mayor intervención estatal (Ward, 2003).

De esta manera, la competencia interurbana por la atracción del capital global (o, a lo menos, altamente móvil) transforma la lógica de planificación territorial 
centralizada característica de las políticas de bienestar. Los gobiernos urbanos ya no estarían administrando los recursos estatales o el estado-nación no estaría coordinando la inversión de capitales fijados al interior de su territorio, sino que los gobiernos urbanos deben promocionar sus espacios locales para atraer, de manera competitiva y fragmentaria, el capital global del cual dependen mayoritariamente. Este es el argumento central para referirse a la transformación de la lógica gerencial a la lógica empresarial de gobernabilidad urbana (Harvey, 1989).

Ahora bien, un aspecto central del pro-empresarialismo urbano es la formación de alianzas público-privadas en el planeamiento, diseño y ejecución de planes y proyectos urbanos (Harvey, 1989; Shin 2009). La formación de estas alianzas es particularmente importante entendiendo que el pro-empresarialismo urbano es una estrategia para la generación de un buen clima empresarial (Harvey, 1989). No obstante, Hackworth (2007) recalca que el pro-empresarialismo urbano no solo se basa en facilitar la operación del mercado sino en comportarse como parte de él. Se promueven espacios locales estableciendo un stock de áreas, zonas, localidades, constituyendo una oferta al interior del mercado inmobiliario. Más allá de facilitar la operación de agentes y corporaciones privadas, el comportamiento empresarial de los gobiernos locales se basa en la transformación institucional y el establecimiento de lógicas privadas en el aparato público (Hackworth, 2007).

El marco teórico del UPE supera la ficción dominante acerca del rol estatal (en el marco del neoliberalismo) como un factor meramente regulador o de corte "managerialista". La teoría del UPE observa al estado como un ente público monopolizador de la toma de decisiones y permeable a las dinámicas y demandas cíclicas y anti-cíclicas de inversión corporativa. Los procesos de rolling-back y rolling-out descritos por Peck \& Tickell (2002) como el retroceso de competencias y atribuciones de regulación del gobierno central y la posterior forma de "devolución" de obligaciones con competencias precarizadas a los gobiernos locales (que en el caso chileno ocurre entre el golpe de estado derechista del año 1973, y el año 1994, cuando se promulga la Ley Orgánica de Municipios), calza en tiempo y contexto político con las dinámicas de UPE.

En resumen, el UPE implica que no sólo el estado opera activamente en la producción de condiciones favorables para el mercado, sino que el mercado opera dentro del estado con sus lógicas de competitividad y su dialéctica de volatilidad versus anclaje espacial del capital (Ward, 2003). De tal forma, el UPE es netamente "neoliberal" en el sentido de que el estado a nivel local: a) promueve la expansión de las lógicas de mercado como reguladores de toda la vida urbana, b) ancla capital volátil al lugar a través de una extrema focalización espacial en las instancias de regulación y planificación del territorio, c) debe responder políticamente frente a la sociedad civil, allí donde no hay ventajas económicas ni sociales aseguradas, y d) es especulativo en el diseño e implementación de sus políticas. 
De esta manera, es útil problematizar sobre pro-empresarialismo urbano en Latinoamérica y, particularmente, en Chile. Mencionar que estudios anteriores como el de Cuenya y Corral (2011) para el caso de Puerto Madero en Buenos Aires, han identificado estrategias pro-empresarialistas de promoción de espacios competitivos para el capital inmobiliario, a través de la gestión de mega-proyectos urbanos. Inscrita en la crisis de la planificación racional-holística de la ciudad, la lógica del pro-empresarialismo urbano ha sido observada en el contexto latinoamericano por De Mattos (2006), en base a la emergencia de nuevas formas de gobernanza urbana $^{10}$ basada en proyectos estratégicos y fortalecimiento de la competitividad interurbana. En la búsqueda por la atracción local de capital, ha sido clave la creciente financiarización del desarrollo inmobiliario (Cattaneo, 2011), así como también la relativa descentralización de las funciones administrativas en algunas ciudades latinoamericanas (De Mattos, 2007).

Particularmente en Chile, la reforma municipal de 1992 ha establecido la descentralización de funciones administrativas más no autonomía fiscal a los gobiernos locales (Montecinos, 2008), lo que coopera también en la adopción de estrategias municipales de promoción de espacios locales para la inversión. Ante la inexistencia de un gobierno metropolitano para el Gran Santiago, y la naturaleza puramente indicativa de los planes regionales de desarrollo urbano, han sido los gobiernos locales de carácter intra-urbano los encargados de re-posicionar al Gran Santiago en lo que respecta a la renovación de espacios centrales. Si bien el debate sobre la participación de los gobiernos locales en desarrollo urbano sigue estando abierta, existe mayor evidencia sobre la progresiva incorporación de alianzas público-privadas en la gobernanza del Gran Santiago ${ }^{11}$ (Zunino, 2001; Nuissl et al., 2012).

$\mathrm{Si}$ bien el pro-empresarialismo urbano ha sido asociado a una escala de competitividad interurbana, en el caso de la renovación urbana en el Gran Santiago es posible identificar escalas intra-urbanas de competitividad, establecida entre comunas centrales y pericentrales del Gran Santiago, dada la ausencia de un gobierno metropolitano que coordine el desarrollo urbano. Según López (2009), la estrategia subsidiaria de renovación urbana impulsada por el estado a principios de los 90' establece un escenario de operaciones entre el sector inmobiliario privado y los gobiernos locales, donde éstos son los encargados de generar las condiciones necesarias para la radicación de la actividad inmobiliaria en sus respectivos territorios (López, 2009).

${ }^{10}$ Concepto utilizado para relevar la menor concentración de poder y toma de decisiones dentro del Estado, y su tendencia a operar como agente de concertación y coordinación de instancias para la toma de decisión entre privados (incluyendo al Estado como el agente que posiciona el interés público dentro de la decisión concertada con los agentes privados).

${ }^{11}$ Rasgo característico del Urbanismo Pro-empresarial. 
En este sentido, cobran importancia los instrumentos regulatorios del espacio urbano -Planes Reguladores Comunales (PRC)-, específicamente la zonificación, definición de usos de suelo y condiciones de edificación (coeficientes de constructibilidad, coeficientes de ocupación de suelo, etc.). No obstante, las disposiciones regulatorias no son la herramienta exclusiva de los gobiernos locales para detonar renovación urbana, lo que retrotrae la distinción entre producción y regulación -municipal en este caso- de las rentas del suelo. La experiencia de la Corporación para el Desarrollo de Santiago ha demostrado que, mediante asociaciones público-privadas de gestión urbana e inmobiliaria, los gobiernos locales pueden participar activamente de la promoción de sus espacios locales para el desarrollo inmobiliario en altura (Contreras, 2005). Es posible que el ejemplo de la CORDESAN pueda replicarse en otras comunas peri-centrales dado los efectos de activación del mercado inmobiliario que ha tenido en Santiago Centro.

Los beneficios de esta actividad inmobiliaria en los municipios están asociados principalmente a los ingresos obtenidos por concepto de permisos de edificación $(1,5 \%$ del presupuesto del proyecto), aglomeración de servicios y patentes comerciales, servicios municipales, y en general la mejora del nivel socioeconómico de las comunas (López, 2009). Por su parte, no existen instrumentos de captura de renta urbana (Torres, 2006), más allá del impuesto territorial recabado por el Servicio de Impuestos Internos (SII) que opera a escala nacional, redistribuyéndose en un $40 \%$ a la comuna respectiva del inmueble y en un $60 \%$ al Fondo Común Municipal (FCM). Si bien éste ha sido calificado como un sofisticado mecanismo de recaudación (Smolka y Amborski, 2003), lo cierto es que no está enfocado a capturar plusvalías -generadas dinámicamente por la apropiación privada del capital fijo externo y la infraestructura pública- y tampoco aplica para los residentes de las nuevas unidades de viviendas, dado que éstas se encuentran en su mayoría con un avalúo exento mediante el decreto DFL-2. No obstante, los beneficios indirectos antedichos instalan la renovación urbana como una forma de aglomerar actividades económicas, intensificar usos de suelo y re-potenciar la economía local de cada comuna.

Dadas las atribuciones de los gobiernos locales actualmente en Chile, es posible deducir que su participación en la promoción de espacios para la atracción de capital inmobiliario está basada en el manejo de los instrumentos regulatorios del suelo (PRC). Si bien la teoría del pro-empresarialismo urbano se asocia usualmente a capitales globales atraídos por mega-proyectos urbanos, en este caso se acota el marco de análisis a los ajustes regulatorios que los municipios deben realizar para concretar el desarrollo urbano en altura.

\section{Metodología}

La metodología utilizada consiste en tres etapas. La primera se enfoca en la revisión de documentos oficiales, que incluye a las memorias explicativas y las 
ordenanzas locales de los Planos Reguladores Comunales y sus respectivas modificaciones vigentes de las comunas de Santiago Centro, Ñuñoa, Recoleta, Quinta Normal, Independencia y Macul. Esta selección se orienta a analizar los ajustes normativos que poseen los municipios frente a la producción inmobiliaria.

La segunda etapa corresponde a la estimación de la renta que los agentes privados capturan a través la producción inmobiliaria. Este valor es denominado RCS-2 (Renta capitalizada de suelo 2), el cual también expresado en términos absolutos (monto total de la renta extraído por proyecto) y términos relativos (divido por la superficie del terreno desarrollado) para establecer comparaciones y develar tendencias. El procedimiento se basa en una herramienta metodológica propia denominada "Ficha de Producción Inmobiliaria" (FIP), construida a partir de datos técnicos de las condiciones de edificación de un proyecto inmobiliario y sus respectivas normativas según la ordenanza local que le rige, siendo los registros municipales de expedientes de edificación (certificado de informaciones previas, aprobación de anteproyecto, permiso de edificación y cuadro de superficies) los necesarios, además de información espacial para poder construirla. Se realizó una revisión de expedientes en el archivo de la Dirección de Obras Municipales de Santiago (DOM), develando las características generales de arquitectura, volumen de la construcción y tipologías de departamentos ofertados al detalle. Estas últimas fueron vinculadas a la revisión de precios de la oferta inmobiliaria en plataformas digitales especializadas (portal inmobiliario.com), para cada proyecto y su correspondiente tipología específica. Sistematizando estos insumos en una tabla de correlaciones (Figura 2) se estima un valor final correspondiente a la renta de suelo capitalizada en cada proyecto por concepto de venta de departamentos, restando costos de producción, derechos municipales (impuesto público a la construcción) y costos blandos (publicidad y difusión), sin contar el gasto por el suelo desarrollado. Como se exprea más arriba, este valor es denominado RCS-2 (Renta capitalizada de suelo 2). 


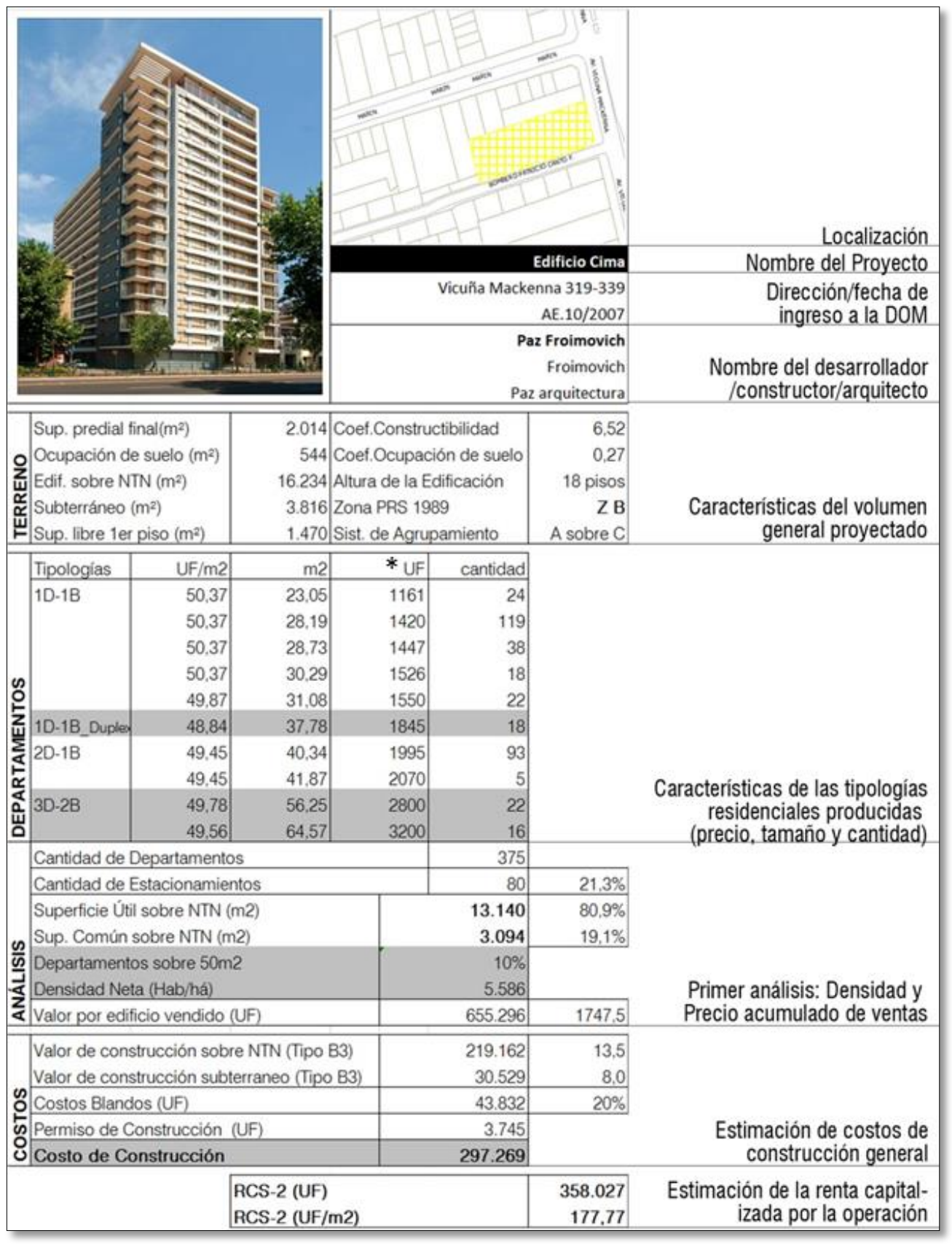

Figura 2. Ficha de producción inmobiliaria (FIP) aplicada a proyectos de renovación urbana residencial privada. Fuente: elaboración propia. (*) UF: La Unidad de Fomento (UF) es una unidad de cuentas utilizada comúnmente en Chile para efectos inmobiliarios y del mercado del suelo reajustable de acuerdo con la inflación. A noviembre del 2013 su valor en pesos chilenos era aproximadamente de $\$ 23.000$ ó US $\$ 46,00$. 
La tercera etapa se basa en la simulación de la renta que un proyecto inmobiliario pudo haber capturado sin considerar el ajuste regulatorio que fue aplicado en él. Este procedimiento consiste en manipular la FIP ajustando las características del proyecto inmobiliario (como altura máxima, coeficiente de constructibilidad, densidad máxima, etc), estableciendo un escenario supuesto donde no hubo aplicación de ajustes contenidos en la ordenanza local del PRC respectivo que permitieran cambios en sus características y así una variación en la renta capturada. Es pertinente mencionar que al poseer la información contenida en el cuadro de superficies del proyecto inmobiliario, la simulación de sus nuevas características resulta ser lo más precisa posible.

\section{Resultados.}

Tipos de ajustes normativos. Permisividad, flexibilidad y direccionalidad.

Al nivel analítico más general, se ha realizado una categorización de diferentes tipos de ajustes normativos que han realizado los municipios del pericentro del Gran Santiago para atraer el capital inmobiliario y aumentar sus rentas potenciales, basado en el comportamiento pro-empresarial de ofertar suelo público y mejorar la competitividad urbana municipal. En algunos casos se observan ajustes regulatorios orientados a entregar mayor permisividad, en otros casos se utilizan incentivos y normas de excepción como las grafica el iError! No se encuentra el origen de la referencia., y en otros casos lo que se hace es direccionar la normativa hacia determinados proyectos con características bastante particulares, incluso generando barreras normativas para excluir a otras formas de desarrollo inmobiliario a menor escala, lo que López Morales $(2011 ;$ 2013a) denomina 'redlining'.

Se obtienen, entonces, tres tipos de ajustes normativos: permisivos, flexibles y dirigidos. A continuación se describen estos tipos de ajustes, y luego se muestra un cuadro que resume las modificaciones realizadas a los PRC estudiados según la categorización respectiva:

1. Permisivos: los ajustes de permisividad se caracterizan por eliminar o reducir abruptamente las restricciones normativas que estaban dispuestas en los instrumentos de planificación, en virtud de maximizar el volumen de producción inmobiliaria habitacional, transfiriendo al productor privado la determinación sobre los aspectos principales de la morfología de los proyectos.

2. Flexibles: los ajustes de flexibilidad se utilizan para entregar incentivos y excepciones que permitan ampliar el volumen producido, siguiendo una lógica de restricciones que pueden ser suplidas por cambios en la morfología, el diseño y el tipo de producto inmobiliario. En esto se distinguen normativas flexibles "por incentivo" y "por excepción".

2.1. Flexibilidad por incentivo: con estos ajustes el municipio permite ampliar el volumen producido a cambio de que el proyecto considere determinados 
aspectos que tengan consistencia con objetivos municipales, propiamente públicos.

2.2. Flexibilidad por excepción: con éstos, el municipio permite ampliar el volumen producido a cambio de que el proyecto ajuste aspectos morfológicos y de diseño, con el fin de que no produzca determinadas externalidades negativas sobre las propiedades aledañas y el espacio público. A diferencia de la flexibilidad por incentivo, el proyecto no internaliza objetivos municipales públicos de desarrollo urbano comunal, sino que resuelve problemas acotados a fin de no impactar con externalidades negativas producto del mayor volumen producido.

3. Dirigidos: los ajustes dirigidos hacen excluyente el desarrollo inmobiliario de renovación urbana, estableciendo características específicas direccionadas a cierto tipo de proyecto, en desmedro de otras formas de producción inmobiliaria alternativas de menor 0 , incluso, de mayor escala.

Permisividad: tipo de ajuste y efecto en la renta potencial de proyectos en Independencia.

A saber, los ajustes normativos más comunes y generalizados corresponden a los ajustes de permisividad. En general, los municipios atraen capital inmobiliario liberando condiciones, entregando al desarrollador privado mayores márgenes de ganancia y decisión sobre el tipo de producto habitacional. En el caso de la comuna de Independencia se observó uno de los ajustes de permisividad más evidentes en relación al resto de los municipios peri-centrales estudiados.

En 2005, el municipio de Independencia aplica una modificación a su plan regulador, heredado de la comuna de Santiago desde 1989. Se modifica una macro-manzana de aproximadamente ocho hectáreas, planificada en 1989 como área verde, con el objetivo de generar en un corto plazo las condiciones normativas favorables para la inversión inmobiliaria, considerando que la aprobación del nuevo PRC podría demorarse demasiado tiempo. Así, se pretendió liberalizar la norma para aprovechar las condiciones de la zona, dotada de buena localización y accesibilidad para proyectos de renovación ${ }^{12}$.

En rigor, lo que se hace es (re)mercantilizar un área verde que según el mismo municipio estaba ubicada "fuera del comercio [sic] de suelo urbano" (de cualquier tipo, no solo renovación urbana), ya que la normativa no permitía su comercialización, constituyendo una expropiación tácita al propietario:

12 "El cambio se refiere a la necesidad de que la Comuna disponga de normas acordes a las necesidades actuales, como asimismo permitir los proyectos de desarrollo que pudieran existir para un sector en crecimiento con una excelente accesibilidad y de privilegiada localización" (Declaración de Impacto Ambiental de la Modificación al PRC de Independencia, 2003: p.4). 
En la práctica, esta zona " $\mathrm{F}$ " [área verde], constituye indirectamente una norma expropiatoria, por cuanto si bien no es un área afecta a utilidad pública, plantea una norma de edificación y de usos de suelo que dan un valor de suelo de cero a los predios que quedan afectos a ella (...) estos [predios] están fuera del comercio del suelo urbano. Es decir, están tácitamente expropiados a valor cero, constituyendo en total una superficie de 3,70 ha, es decir el $42 \%$ del total de la macro manzana, que bajo esta norma, no podrá ser renovado (Declaración de Impacto Ambiental de la Modificación al PRC de Independencia, 2003: p.10).

Lo interesante es que la anterior zonificación de área verde había sido orientada funcionalmente a la renovación urbana (área verde para la densificación según el PRC de Santiago) y, sin embargo, posteriormente es vista como norma expropiatoria y como factor de des-mercantilización del suelo. Por tanto, lo que se hace en Independencia es desregular una planificación anterior y funcional al mismo proceso de renovación urbana. El plan de la comuna de Santiago tenía prevista esta zona como una de las principales áreas verdes que darían sustento a la densificación del pericentro norte, por lo que su posterior desregulación y apertura al mercado de suelo habitacional de alta densidad implica una contradicción al interior del mismo esquema de planificación de la renovación urbana residencial.

En efecto, además del cambio de uso de suelo, el incentivo en normas de edificación fue altísimo, con un máximo de ocupación de suelo de 1 (100\% del predio), y altura libre $^{13}$ para edificaciones aisladas. Esto generó una rápida y explosiva actividad inmobiliaria que transformó radicalmente el paisaje urbano en Independencia, precisamente en esta zona y sectores aledaños, lo cual es revelado por la asesora urbanista del municipio:

[P]ara dinamizar esta zona [...] la idea es que obviamente [se] castigó las áreas verdes de manera increíble [...] Entonces hoy día [el Plan Regulador] lo permite todo. $\mathrm{Y}$ acá fue extremadamente agresivo porque aumentaron ${ }^{14}$ a un $100 \%$ la ocupación del suelo. Aumentaron de 4 a 8 pisos la fachada continua. Entonces de eso se está aprovechando la empresa que está aquí al lado (Entrevista a Asesora Urbanista de Independencia, realizada en Junio de 2012).

En la zona en particular se han desarrollado sólo dos proyectos, pero de gran intensidad, denominados Portal Independencia y Su Independencia, de las inmobiiarias Eurocorp y Su K-sa, respectivamente. El proyecto Portal Independencia ha constado de dos edificios de más de 20 pisos, construidos en dos fases, entre 2011-2013, con más de 500 departamentos cada uno. Este solo proyecto ha

\footnotetext{
13 Según artículo 2.6.3. de la Ordenanza General de Urbanismo y Construcciones (OGUC).

${ }^{14}$ En ese momento el Asesor Urbanista era Enrique Barba, correspondiente a la gestión anterior del mismo Alcalde.
} 
producido $23.882,17 \mathrm{~m}^{2}$ en la zona modificada, lo que se aproxima a un $10 \%$ de la superficie total construida en la comuna desde la aplicación de la modificación en 2005 hasta 2011 (López Morales et al., 2012). Por su parte, el proyecto Su Independencia, de 25 pisos, produjo un total de 704 departamentos, siendo el segundo proyecto con más unidades de vivienda dentro de todo el sector pericentral estudiado en esta investigación (seis comunas), lo que determinó una alta tasa de acumulación de 17, sobre un precio de compra de suelo de 5,12 UF/m². Ambos proyectos desarrollados en esta misma manzana, modificada por el PRC, se caracterizan entonces por producir cantidades importantes de vivienda, con unidades pequeñas de $30 \mathrm{~m}^{2}$ que bordean precios en torno a las $1.000 \mathrm{UF}$.
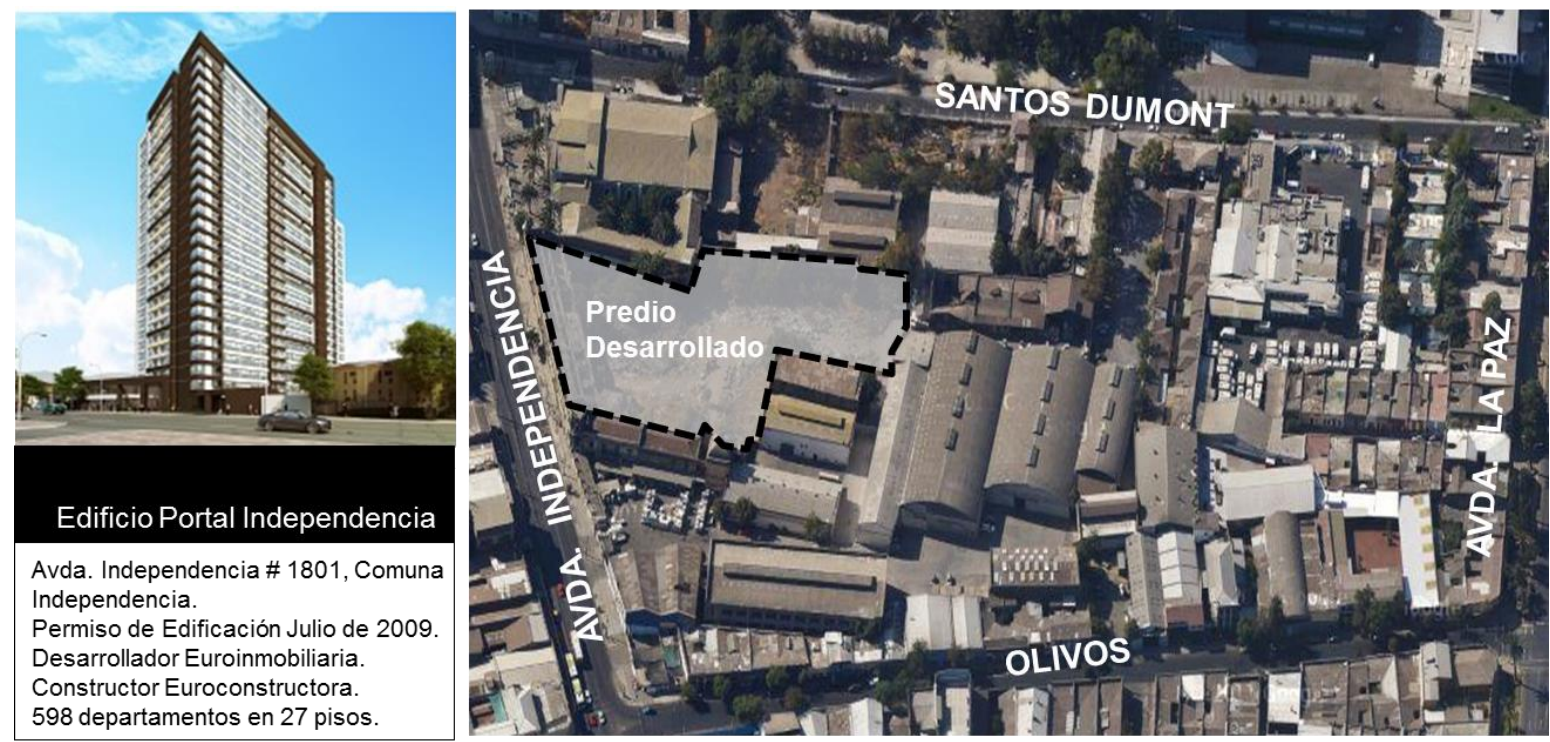

Figura 3. Caso de Normativa Permisiva. Edificio Portal Independencia, comuna Independencia. Fuente: Elaboración propia.

Pero esta situación no solo es imputable a la modificación respectiva, sino que obedece al mercado instalado en la comuna de Independencia, que se caracteriza por la producción de proyectos con altísima cantidad de unidades ofertadas, siendo el principal atributo de la oferta inmobiliaria de esta comuna respecto al conjunto del peri-centro. Es la zona con mayor cantidad de departamentos por proyecto, con una media de 511 unidades; y donde se encuentran 4 de los 10 proyectos con más departamentos que se han registrado en las seis zonas estudiadas.

Ahora bien, esto está fundamentalmente determinado por la presencia activa de la inmobiliaria Eurocorp en Independencia, que se caracteriza por producciones de gran cantidad de departamentos. Eurocorp produce más del $50 \%$ del material edificado en dicha comuna, y ha desarrollado 7 de los 10 proyectos con más departamentos del pericentro estudiado. Esta instalación de Eurocorp en la comuna de Independencia ha generado un modelo de producción muy intensiva que 
presionó en 2002 para modificar el PRC y penetrar hacia una zona estratégicacentral de la comuna otrora proyectada como área verde.

La categoría de "permisividad" se presenta, entonces, en términos de la necesidad de ajustar el PRC entregando condiciones casi irrestrictas a la producción inmobiliaria intensiva. Esto se hizo sobre una manzana determinada, según se relata más arriba, la cual estaba frenando el desarrollo inmobiliario, dadas las escasas modalidades de articulación del proceso de renovación urbana con la existencia de parques o áreas verdes para su sostenimiento.

Normativas flexibles: tipo de ajuste y efecto en la renta potencial de proyectos Recoleta.

Tras cerca de siete años de elaboración, al año 2005 la comuna de Recoleta presenta su nuevo PRC y así el territorio comunal deja de ser regido por zonificaciones provenientes de planes reguladores de Santiago Centro y Conchalí, donde sus normativas eran muy permisivas tanto en usos de suelo como en condiciones de edificación. Sumado a esto, durante el proceso de elaboración del plan, la comuna experimentó dos procesos complementarios; el mejoramiento en el acceso a la comuna a través de inversión estatal en obras viales, y un incremento de la producción inmobiliaria de renovación urbana (López Morales, Gasic, Meza, 2012).

El Plan Regulador Comunal de Recoleta otorga especial importancia a la promoción del desarrollo urbano comunal, atendiendo estrategias para atraer capital inmobiliario en espacios deteriorados, encontrando en la ordenanza local un tipo de ajuste normativo enfocado en generar condiciones de excepción a proyectos inmobiliarios que les permite incrementar su volumen construido. En este caso observamos que el artículo 3.3.6 de la Ordenanza denominado "Normas de Excepción" permitiría a un proyecto que no esté situado en zonas establecidas por la Ordenanza, como sectores patrimoniales ni en el Barrio Bellavista, disponer de un beneficio de aumento del coeficiente de constructibilidad hasta en un $40 \%$ y extensión de alturas máximas, mientras cumplan necesariamente con ciertas condiciones propuestas ${ }^{15}$

15 Condición de Dimensión del Predio: hace referencia a dos condiciones; que el tamaño predial donde será construido el proyecto sea de a lo menos $1.200 \mathrm{~m}^{2}$ y también éste debe localizarse en una calle con un ancho mínimo de $20 \mathrm{~m}$. Condición de Edificación: cuando la edificación excede la altura máxima este artículo fija la rasante del proyecto en $70^{\circ}$ respetando un distanciamiento mínimo de $5 \mathrm{~m}$ a los divisorios. Condición de Urbanización y Espacio Público: si el proyecto pretende obtener el beneficio deberá contemplar las condiciones expuestas en el artículo 3.1.2 de la misma Ordenanza, y así ceder o proveer de terreno para vialidad y áreas verdes, además de consultar espacios libres a nivel de acera y adyacentes a ella, en un $5 \%$ de la superficie del terreno. 
A pesar de la cantidad importante de restricciones, algunas empresas inmobiliarias estimuladas por el atractivo beneficio, comenzaron a formular proyectos que se ajustaran a las características que exigía el artículo, y ya para el año 2006 la DOM había acogido y aprobado uno, evidenciando que podría resultar ser un ajuste efectivamente llamativo, ya que le permitió al proyecto "Edificio Recoleta Plaza" de la inmobiliaria Grupo Activa acceder también a él.

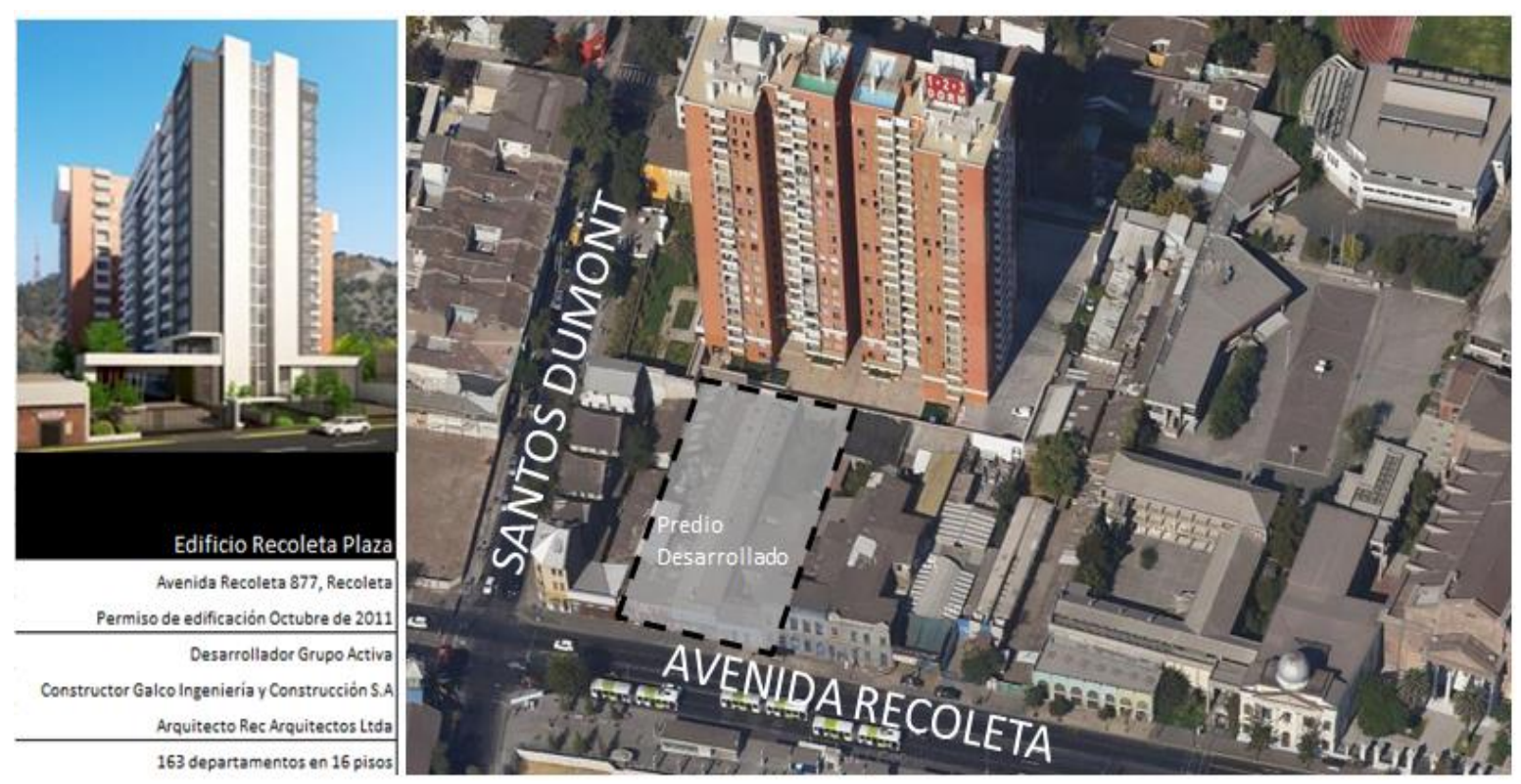

Figura 4. Caso de Normativa Flexible. Edificio Recoleta Plaza, comuna de Recoleta. Fuente: Elaboración propia.

El proyecto está localizado en la intersección de Av. Recoleta y Santos en la comuna de Recoleta, y contempla construir 163 departamentos con precios que van de las 1.274 a 2.158 UF. Para construirlo fue necesaria la compra de tres propiedades juntas a Av. Recoleta, done la inmobiliaria las compró por un total de 23.812 UF, pagando en promedio $13,01 \mathrm{UF} / \mathrm{m}^{2}$. La superficie predial total donde el edificio fue construido era de $1.829 \mathrm{~m}^{2}$, permitiéndole al proyecto ajustarse a la condición de dimensión del predio. Debido a que su altura máxima excede lo permitido según la zona en donde se localiza, puede aumentarla aunque asumiendo la fijación de la rasante, acogiendo de este modo la condición de edificación, y dadas las dimensiones del proyecto, éste posee espacio suficiente para proveer del porcentaje requerido a vialidad y áreas verdes establecidas por la condición de urbanización y espacio público.

El proyecto acepta las tres condiciones propuestas por la ordenanza local, permite generar un mayor volumen útil de viviendas destinadas a la venta y logra beneficiar notablemente a sus desarrolladores al explotar con mayor intensidad la renta del suelo, haciendo más amplia la diferencia respecto al precio pagado por los predios. 
Se debe considerar que un proyecto inmobiliario localizado en la zona A1 (una zona destinada a la edificación en altura en torno a Av. Recoleta, desde el límite sur de la comuna hasta la intersección con la Av. Cardenal José María Caro), puede contar con un coeficiente de construcibilidad máximo de 3,5 y una altura que no debe sobrepasar los $38 \mathrm{~m}$ de altura ó 14 pisos. Con el ajuste normativo el coeficiente de construcibilidad se pudo fijar en 4,7 (de 4,9 como máximo permitido) permitiéndole construir al proyecto dos pisos adicionales y sumar $877 \mathrm{~m}^{2}$ de superficie útil. La información contenida en el cuadro de superficies asociado al último permiso de edificación, muestra que la superficie útil construida hasta el piso 14, que hubiera sido el máximo permitido según la norma, era de $6.171 \mathrm{~m}^{2}$, lo que gracias al ajuste varió a $7.049 \mathrm{~m}^{2}$.

Esta diferencia es importante, porque implica a su vez una variación significativa en el nivel de utilidad absorbida por el desarrollador inmobiliario, ya que sin la aplicación del flexible ajuste, ésta hubiera sido estimada en 78.120 UF (primera barra) al vender 141 departamentos (las características del proyecto indican que los pisos se duplican exactamente desde el 4 hasta el último, por lo que una variación del 14 a 16 supondría la misma lógica), mientras que el escenario real muestra que fue de 95.435 UF (segunda barra) vendiendo 161 viviendas. Existe en aquella cantidad de metros cuadrados adicionales una utilidad de 17.315 UF absorbidas completamente por Grupo Activa que reflejan un aumento en la explotación de la renta del suelo en un $18 \%$.

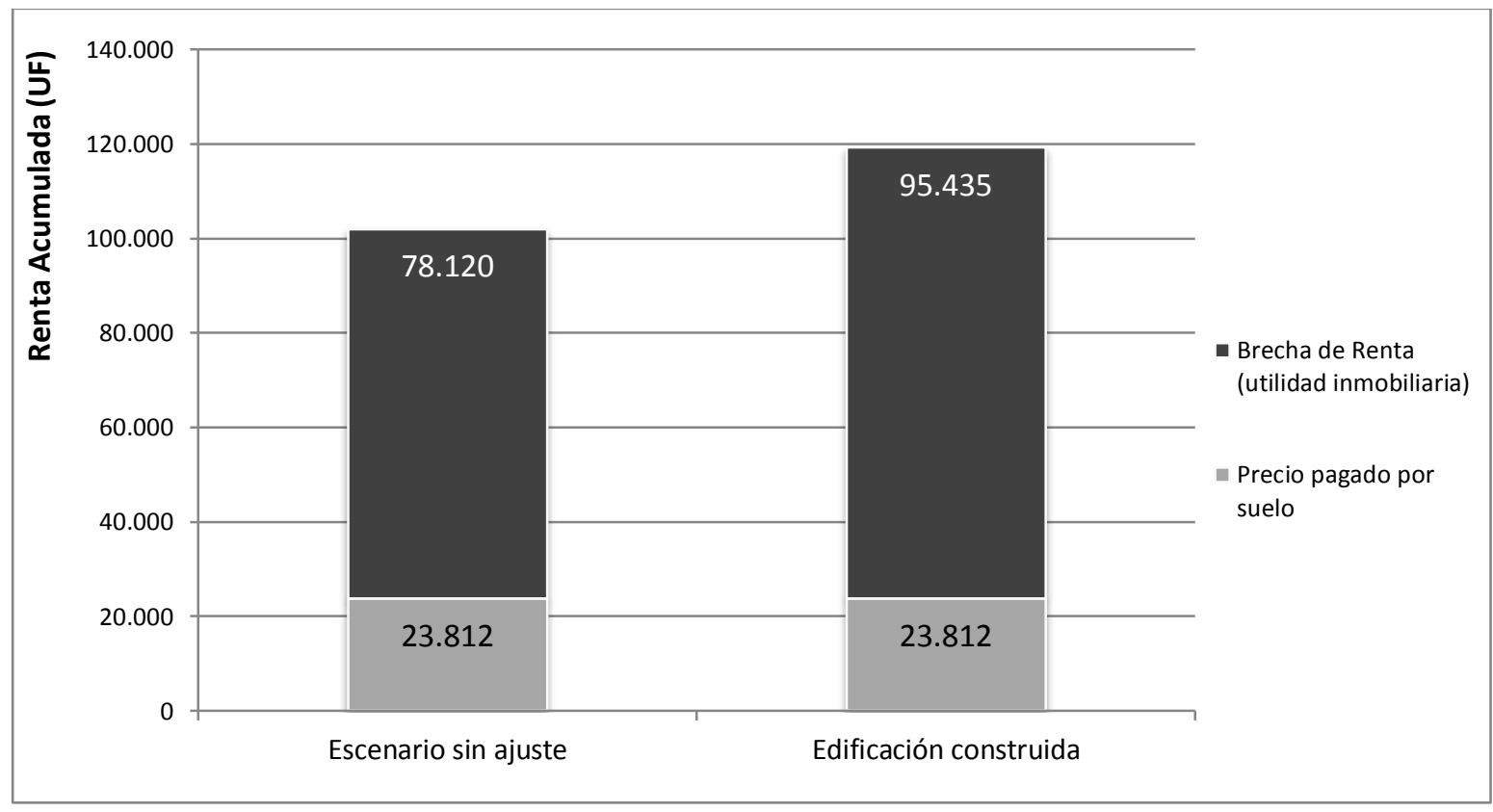

Figura 5. Gráfico de comparación de la renta inmobiliaria (RSC-2) y el precio pagado por el suelo (RCS-1) para las tres situaciones. Fuente: Elaboración propia. 
La creación de este tipo de ajuste es acorde a la necesidad de la comuna por promover el desarrollo urbano dentro de un marco de competencia entre gobiernos locales, proponiendo atractivos cambios normativos y atrayendo a desarrolladores inmobiliarios por medio de ajustes flexibles, limitándole ciertas características a sus proyectos a cambio de un aumento considerable en la superficie útil.

Normativas ad hoc: tipo de ajuste y efecto en la renta potencial de proyectos en Ñuñoa.

Aunque menos frecuente en la disposición de instrumentos regulatorios del suelo, es posible distinguir una tercera categoría de normativas dirigidas. Los municipios utilizan este tipo de regulación, estableciendo una franja de acción con alto grado de especificidad, excluyendo el desarrollo de una producción inmobiliaria que no se ajuste a aquello establecido. En el caso de la comuna de Ñuñoa esto puede observarse en el llamado Seccional Irarrázaval, modificación en torno al propio eje que promueve la producción inmobiliaria más intensa. Si bien a priori, esta modificación al PRC se asocia a una modificación permisiva, una observación refinada permite percibir importantes límites que la vinculan con una categoría más específica, de carácter dirigida.

En 2004, luego de quince años de operación del PRC, el municipio de Ñuñoa aplica la modificación de mayor repercusión hasta ahora. Se modifica la normativa establecida para las manzanas de borde del eje intercomunal de Avenida Irarrázaval, con la intención de detonar el proceso de verticalización ya que la falta de desarrollo, según el municipio, era el causante de la incapacidad de materializar el ancho proyectado total de 35 metros para la vía y el despoblamiento, producido por el deterioro de los inmuebles y la falta de normas técnico urbanísticas que permitan la renovación.

Si bien el PRC de 1989 ya proponía ésta como una zona para densificación, con altura libre según rasante. No obstante, esta modificación incorpora un importante aumento de constructibilidad máxima y una aún mayor altura, a través del establecimiento de edificación continua en la primera crujía y sobre esta edificación aislada. Dicho esquema normativo, incorporado en la normativa de la comuna de Santiago desde 1990, permite considerar la aplicación de rasante desde la altura máxima de edificación continua, lo que aumenta considerablemente el volumen teórico.

El discurso municipal respalda el incremento de las condiciones normativas para capitalizar la infraestructura vial ya dispuesta, equipamientos de diferentes escalas (centro comunal, boulevard comercial, dos líneas de metro y vías intercomunales) por medio de la construcción. Si bien, reconoce la existencia de la demanda por construcción de vivienda en altura, para que ella se materialice es necesario que la municipalidad otorgue "mejores condiciones normativas, que hagan factible la 
inversión con adecuados niveles de rentabilidad" (Memoria Explicativa de la Modificación al Plan Regulador de Ñuñoa, 2003: 5).

Contrario a lo que se expone en la memoria de la modificación, que plantea que "la propuesta pretende ser un detonante para el desarrollo del uso residencial, sin alterar los cupos de constructibilidad y de infraestructura sanitaria ya establecida para el área" (Memoria Explicativa de la Modificación al Plan Regulador de Ñuñoa, 2003: 5), esta modificación, como muestra la Tabla 1, en la práctica aumenta en forma considerable el volumen edificable.

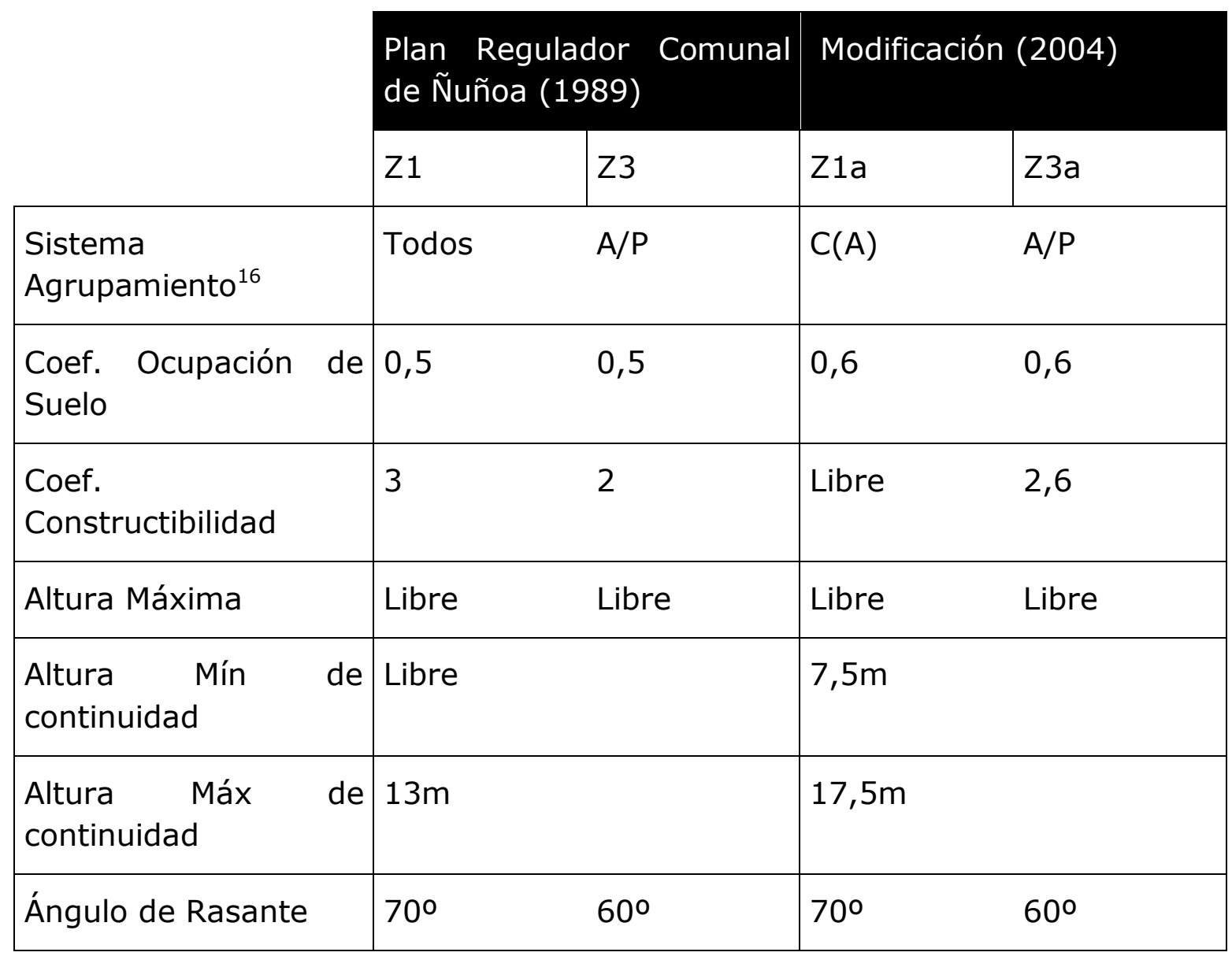

Cuadro 1. Gráfico de comparación de la renta inmobiliaria (RSC-2) y el precio pagado por el suelo (RCS-1) para las tres situaciones. Fuente: Elaboración propia.

Esta modificación consiguió el objetivo explícito de detonar un intenso proceso de edificación de uso residencial, desarrollando la construcción de proyectos que

\footnotetext{
${ }^{16}$ Sistema de agrupamiento: $\mathrm{A}=$ Aislado, construcciones separadas de todos los deslindes; $\mathrm{P}$ $=$ Pareado, construcciones que comparten un deslinde común; $\mathrm{C}=$ Continuo, construcciones que ocupan todo el frente compartiendo ambos deslindes; y $C(A)=$ Aislado sobre continuo, construcción tipo continua hasta cierta altura que continua por sobre ella de manera aislada.
} 
superaban notablemente las construcciones desarrolladas en etapas anteriores. La mayor incidencia estuvo en el sector poniente de la comuna, donde la construcción de edificaciones en el periodo anterior de quince años (1989-2003) era de sólo $94.318 \mathrm{~m}^{2}$ construidos, notoriamente menor al periodo de siguiente de tres años (2004-2007) en que se edificaron 325.973 metros cuadrados. Si bien un porcentaje mayor al $60 \%$ de los proyectos se localizó fuera de la propia área de aplicación de la modificación, la percepción de un proceso generalizado de renovación suscitado producto del aumento exponencial del número de proyectos en construcción y la mayor envergadura de estos.

Una primera lectura entonces indicaría una modificación más bien permisiva, que incrementa notablemente el potencial constructivo de coeficiente de constructibilidad (de 3 a sin restricción) y altura, mediante el aumento de la altura máxima de edificación continua y con ello de aplicación de rasante. No obstante, existe un aspecto en dicha modificación que generó una clara exclusión, determinando límites para el mínimo edificable. Ésta fue el cambio de norma para permitir exclusivamente edificación continua, fijando un mínimo de altura de edificación continua de 7,5 metros ( 3 pisos), y posibilitando -sobre ésta- una edificación aislada de mayor altura.

De esta manera entonces se genera una importante exclusión en la posibilidad de edificar, estableciendo una franja de posibilidades de acción. Esto es una modificación dirigida, que define quién construye por medio de qué específicamente se construye. La exclusión entonces de pequeños actores productores inmobiliarios, tanto residentes con capacidad de producir como pequeños inmobiliarios, queda definida no sólo por el aumento del valor del suelo ${ }^{17}$, sino también por exigencias morfológicas asociadas al volumen producido. Por ende, se trata de una norma dirigida, que significa el establecimiento acotado de condiciones normativas, referidas a la capacidad normativa del actor dominante, es decir ad-hoc a la acción de las empresas inmobiliarias, suprimiendo simultáneamente la operación de otros actores sociales.

Es el caso de la inmobiliaria Actual y su acción en la comuna. Se estimaba hasta el año 2010 que el 10\% de la producción inmobiliaria en Ñuñoa correspondía a esta empresa, desarrollando proyectos que están dentro de los de mayor envergadura. El proyecto Edificio Nueva Irarrázaval, desarrollado por la inmobiliaria Actual a partir de 2008, es un caso que grafica esta modificación de manera elocuente. Ubicado en el borde de la Avenida Irarrázaval (zona Z1, y luego Z1a), alcanza la altura de 22 pisos con una cantidad de 192 departamentos en $15.120 \mathrm{~m}^{2}$ construidos, materializando un coeficiente de constructibilidad $^{18}$ de 7,53. Con la normativa

17 Que desde fines de 1990 a 2004 es alrededor de 12UF/m2, para subir por sobre las $16 U F / m 2$ entre 2004 y 2007.

${ }^{18}$ Ratio floor area. 
anterior (Z1), este proyecto podría haber alcanzado bastantes pisos menos, principalmente porque el coeficiente normado anteriormente era de 3. Considerando que existen artículos en la LGUC y OGUC para aumentar las disposiciones establecidas en la ordenanza local del PRC, que permiten elevar el coeficiente de constructibilidad hasta un $156 \%{ }^{19}$, aumenta en este caso el coeficiente de 3 a 4,83.
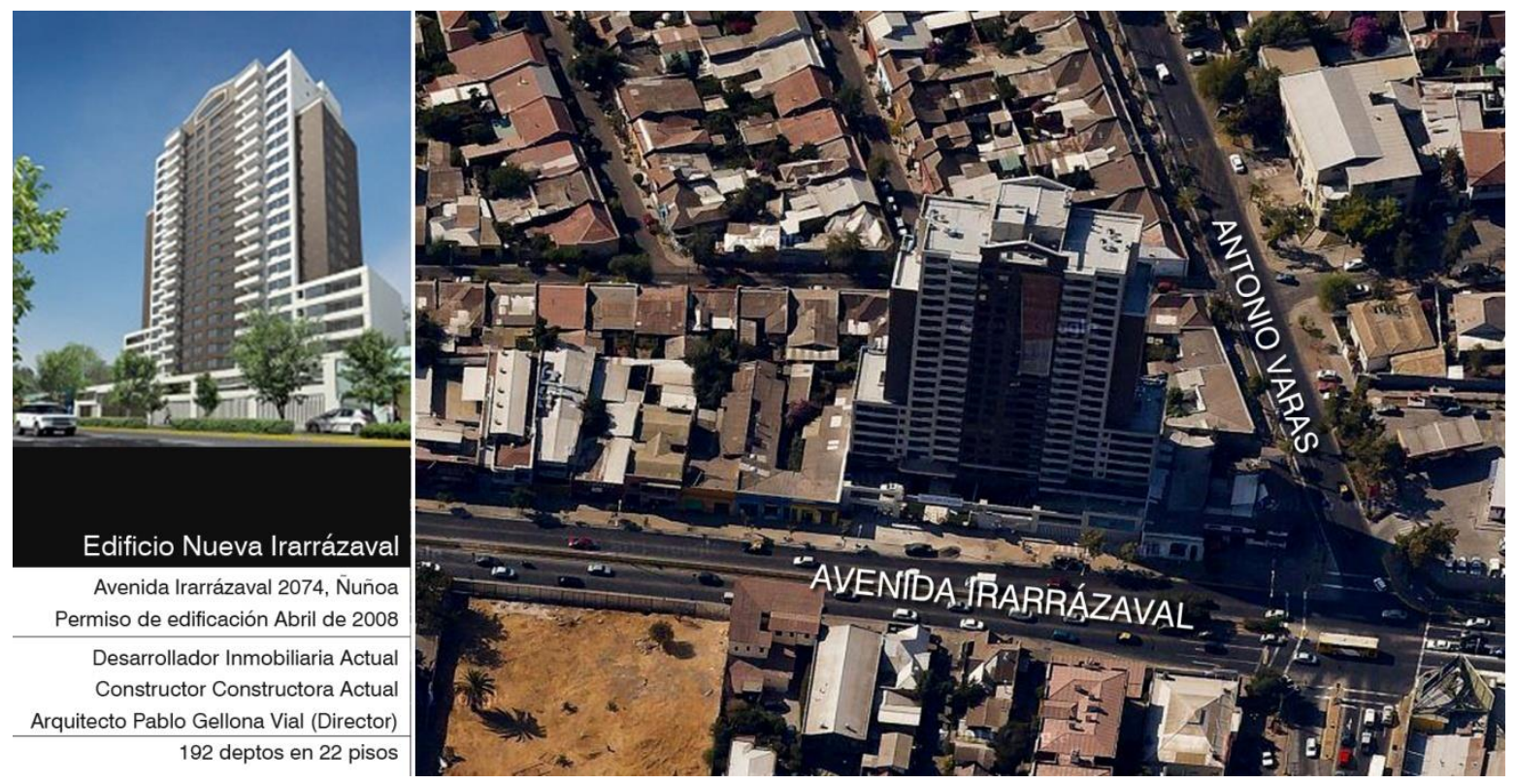

Figura 6. Caso de Normativa Dirigida. Edificio Nueva Irarrázaval, comuna de Ñuñoa. Fuente: Elaboración propia.

Es así como se posibilitan tres escenarios: a) situación anterior según norma Z1 sin beneficios de norma de excepción, b) situación anterior según norma Z1 con beneficios de norma de excepción, y c) situación de edificio construido con Z1a, donde la norma de excepción no es relevante ya que se libera el coeficiente de constructibilidad máximo ${ }^{20}$. La Figura 7 grafica la incidencia de la norma en cada caso donde un escenario A posibilitaría la construcción de un edificio de 8 pisos de 76 departamentos con una utilidad inmobiliaria de 52.196UF, con una tasa de acumulación de 1,36 (1,36 veces sobre el costo del terreno). Luego un escenario $B$, con el incremento de constructibilidad de la Ley General, posibilitaría un edificio de 13 pisos de 123 departamentos con una utilidad inmobiliaria o brecha de renta de 109.206UF, con una tasa de acumulación mayor de 2,9. Finalmente el tercer escenario C, con las disposiciones regulatorias de la modificación de 2004, posibilitó

19 El artículos 63 de la Ley General de Urbanismo y Construcciones o LGUC, ofrece un incremento de $30 \%$ en la constructibilidad por fusión de terrenos; y el artículo 6.1.5. de la Ordenanza General de Urbanismo y Construcción o OGUC, que permite descontar la superficie construida en áreas comunes del cálculo de constructibilidad cuando éstas no superan el $20 \%$ del total edificado.

20 Para el cálculo de simulación se considera de referencia el departamento promedio de $63,55 \mathrm{~m} 2$ de $2600 U \mathrm{~F}$ y las diferentes tipologías de la planta. 
la construcción de un edificio de 22 pisos de 196 departamentos con una utilidad inmobilairia de 191.396UF, y una tasa de acumulación de 5,08. En términos de derechos municipales por construcción, correspondientes al 1,5\% del presupuesto de construcción ${ }^{21}$, los escenarios A, B, y C significarían 1088UF, 1754UF y 2734UF respectivamente.

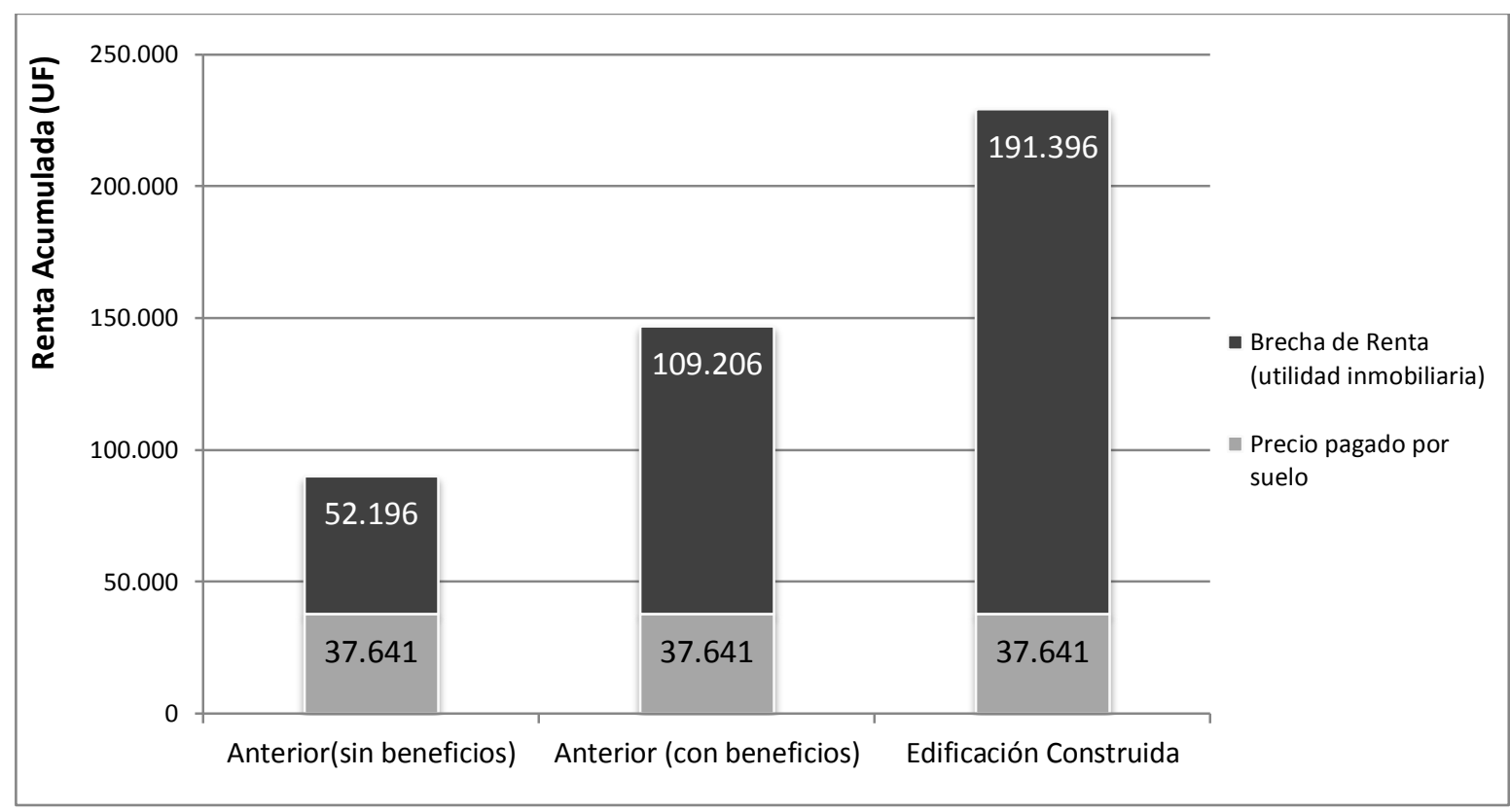

Figura 7. Gráfico de comparación de la renta inmobiliaria (RSC-2) y el precio pagado por el suelo (RCS-1) para las tres situaciones. Fuente: Elaboración propia.

${ }^{21}$ Según el árticulo 5.1.4. de la Ordenanza General de Urbanismo y Construcción o OGUC es posible disminuir los derechos municipales por permiso de edificación al repetir unidades y plantas, en hasta50\%. 
Normativas Combinadas: tipo de ajuste y efecto en la renta potencial de proyectos en Santiago.

Finalmente, complementando el relato expuesto anteriormente, se presenta el caso de normativas combinadas en la comuna de Santiago, específicamente en torno a la Avenida Santa Isabel, la zona de mayor intensidad de producción inmobiliaria de la comuna y probablemente del país. Esta área ha atravesado una serie de modificaciones normativas, realizadas en el marco del plan de repoblamiento y la aceleración del mercado de producción inmobiliaria, reajustándose las disposiciones siguiendo las diferentes fases del proceso de renovación. Analizado un periodo de dos décadas, es posible observar estos reajustes, asociando las categorías anteriormente desarrolladas, para un análisis de distintos momentos de un mismo proceso.

Para comenzar, es necesario remontarse al establecimiento del PRC de Santiago en 1990. Este PRC contiene una normativa general permisiva, sin mayores diferencias en las tres principales zonas de edificación. La mayor diferencia es el grado de permisividad. En las tres principales zonas se establece la edificación sin altura máxima establecida, es decir, libre según rasante de $70 \%$. Al permitir en toda la comuna el sistema de construcción continua, la altura de aplicación de esta rasante depende de la altura máxima de esta edificación continua, la cual varía entre 14 metros ( 5 pisos) hasta 45 metros (18 pisos) en el triángulo central.

Dentro de esta normativa permisiva, durante los noventa se realizan una serie de seccionales específicos, que tenían por objetivo generar las condiciones para la materialización de proyectos detonantes. Es el caso de los Seccionales de Santa Isabel decretados entre 1995 y 1996. Este seccional, más que ser una normativa permisiva que promueva la inversión mediante la liberalización de las condiciones normativas, se propone como una normativa dirigida que limita con un nivel bastante restrictivo los actores que puedan operar $y$, por otro lado, a nivel tributario, genera beneficios y sobretasas dirigidas a quienes construyan o no en la zona respectivamente. Normativamente se aplica un coeficiente de constructibilidad mínimo de 2, lo cual deja fuera cualquier construcción de menos de cuatro pisos. A su vez se establecen varias subzonificaciones con establecimiento de superficies prediales mínimas bastante altas (1.000, 2.000, 5.000 metros cuadrados).

En segundo lugar estaría la derogación de los mismos seccionales en la actualización del texto de la ordenanza local, luego de la detonación del mercado de renovación en la zona. Si bien esta no es propiamente tal una modificación explícita, sino más bien es una derogación donde el seccional Santa Isabel es el único que no se incorpora a la ordenanza local, perdiendo vigencia y volviendo a la condición anterior. Esto permite desarrollar predios desde 500 metros cuadrados de superficie, lo que significa la apertura de un importante obstáculo, considerando que los desarrolladores buscan gestionar la compra de suelo barato y deben comprar 
una serie de terrenos. Inmediatamente se genera un proceso de intensa producción en 2006 hasta 2009, frenada en parte por los efectos de la crisis económica. Importa notar que los proyectos desarrollados en ese período corresponden a los más intensivos en suelo, comparado con el resto de las zonas de renovación urbana consideradas en este estudio. Se desarrollan proyectos en superficies prediales de entre 1.000 y $1.500 \mathrm{~m}^{2}$, lo que habla de una renovación intensiva en suelo, torres en forma rectangular tipo "galleta" (A) que se insertan de forma perpendicular a un cuerpo paralelo a la calle en edificación continua (B), tipología que derivada de la derogación del seccional Santa Isabel.

Por último, en 2011 está la modificación de un tercio del territorio comunal correspondiente a los sectores Barrio Universitario y Expansión del Centro del proceso de actualización del PRC. En esta modificación se parte de la base de la saturación inmobiliaria en la zona, estableciendo alturas y coeficientes de constructibilidad bastante menores a los posibilitados anteriormente ( 9 pisos donde anteriormente se construía más de 30 pisos). Lo interesante de esta última modificación es el carácter flexible de la normativa, permitiendo sobrepasar los nueve pisos y coeficientes de constructibilidad de 3,6 normados para los proyectos en torno a tres ejes, Santa Rosa y Vicuña Mackenna (en dos pisos y 0,7 coeficiente de constructibilidad), y Santa Isabel (en cuatro pisos y 1,4 coeficiente de constructibilidad).

\begin{tabular}{|c|c|c|c|c|c|c|c|c|c|}
\hline \multirow[b]{2}{*}{ ZONAS } & $\begin{array}{l}1990- \\
1995\end{array}$ & \multicolumn{4}{|c|}{$1995-2006$} & $\begin{array}{l}2006- \\
2011\end{array}$ & \multicolumn{2}{|l|}{2011} & \\
\hline & B & B1 & B1a & B1b & B1c & B & B & B2a & B2a \\
\hline $\begin{array}{l}\text { Superficie predial } \\
\text { mínima }\end{array}$ & 500 & 1000 & 5000 & 2000 & 500 & 500 & 500 & 500 & 500 \\
\hline $\begin{array}{l}\text { Coef máximo de } \\
\text { ocup de suelo }\end{array}$ & 1 & 0,8 & 0,8 & 0,8 & 0,8 & 1 & 0,7 & 0,7 & 0,7 \\
\hline $\begin{array}{ll}\text { Sistema } & \text { de } \\
\text { Agrupamiento } & \end{array}$ & A-P-C & $\begin{array}{l}\text { A-P- } \\
C\end{array}$ & $\begin{array}{l}\text { A-P- } \\
C\end{array}$ & $\begin{array}{l}\text { A-P- } \\
\text { C }\end{array}$ & $\begin{array}{l}\text { A-P- } \\
\text { C }\end{array}$ & A-P-C & $A-P-C$ & $\begin{array}{l}\text { A-P- } \\
C\end{array}$ & $\begin{array}{l}\text { A-P- } \\
\text { C }\end{array}$ \\
\hline $\begin{array}{l}\text { Altura mínima edif. } \\
\text { Continua }\end{array}$ & $\begin{array}{l}\text { no } \\
\text { aplica }\end{array}$ & $\begin{array}{l}\text { no } \\
\text { aplic } \\
\text { a }\end{array}$ & $\begin{array}{l}\text { no } \\
\text { aplic } \\
\text { a }\end{array}$ & $\begin{array}{l}\text { no } \\
\text { aplic } \\
\text { a }\end{array}$ & $\begin{array}{l}\text { no } \\
\text { aplic } \\
\text { a }\end{array}$ & $\begin{array}{l}\text { no } \\
\text { aplica }\end{array}$ & $\begin{array}{l}\text { no } \\
\text { aplica }\end{array}$ & $\begin{array}{l}5,5 \mathrm{~m} \\
(2)\end{array}$ & $\begin{array}{l}5,5 \mathrm{~m} \\
(2)\end{array}$ \\
\hline $\begin{array}{l}\text { Altura máxima } \\
\text { edif. Continua }\end{array}$ & $\begin{array}{l}35 \mathrm{~m} \\
(14)\end{array}$ & $\begin{array}{l}35 \mathrm{~m} \\
(14)\end{array}$ & $\begin{array}{l}35 \mathrm{~m} \\
(14)\end{array}$ & $\begin{array}{l}35 \mathrm{~m} \\
(14)\end{array}$ & $\begin{array}{l}35 \mathrm{~m} \\
(14)\end{array}$ & $\begin{array}{l}35 \mathrm{~m} \\
(14)\end{array}$ & $22,5(9$ & $\begin{array}{l}32,5 \\
(13)\end{array}$ & $\begin{array}{l}27,5 \\
(11)\end{array}$ \\
\hline
\end{tabular}




\begin{tabular}{|c|c|c|c|c|c|c|c|c|c|}
\hline $\begin{array}{l}\text { Aislado sobre } \\
\text { continuo }\end{array}$ & sí & Sí & sí & sí & no & sí & no & no & No \\
\hline $\begin{array}{l}\text { Coef mínimo de } \\
\text { constructibilidad }\end{array}$ & $\begin{array}{l}\text { no } \\
\text { aplica }\end{array}$ & 1,5 & 2,2 & 2,2 & $\begin{array}{l}\text { no } \\
\text { aplic } \\
\text { a }\end{array}$ & $\begin{array}{l}\text { no } \\
\text { aplica }\end{array}$ & $\begin{array}{l}\text { no } \\
\text { aplica }\end{array}$ & $\begin{array}{l}\text { no } \\
\text { aplic } \\
\text { a }\end{array}$ & $\begin{array}{l}\text { no } \\
\text { aplic } \\
\text { a }\end{array}$ \\
\hline $\begin{array}{l}\text { Coef máximo de } \\
\text { constructibilidad }\end{array}$ & $\begin{array}{l}\text { no } \\
\text { aplica }\end{array}$ & $\begin{array}{l}\text { no } \\
\text { aplic } \\
\text { a }\end{array}$ & $\begin{array}{l}\text { no } \\
\text { aplic } \\
\text { a }\end{array}$ & $\begin{array}{l}\text { no } \\
\text { aplic } \\
\text { a }\end{array}$ & $\begin{array}{l}\text { no } \\
\text { aplic } \\
\text { a }\end{array}$ & $\begin{array}{l}\text { no } \\
\text { aplica }\end{array}$ & 3,6 & 5 & 4,3 \\
\hline $\begin{array}{l}\text { Exigencia } \\
\text { estacionamientos }\end{array}$ & $\begin{array}{l}1 \\
\text { est/5 } \\
\text { viv }\end{array}$ & \begin{tabular}{|l}
1 \\
est/5 \\
viv
\end{tabular} & $\begin{array}{l}1 \\
\text { est/5 } \\
\text { viv }\end{array}$ & $\begin{array}{l}1 \\
\text { est/5 } \\
\text { viv }\end{array}$ & $\begin{array}{l}1 \\
\text { est/5 } \\
\text { viv }\end{array}$ & \begin{tabular}{|l}
1 \\
est/5 \\
viv
\end{tabular} & $\begin{array}{l}1 \text { est } / 2 \\
\text { viv }\end{array}$ & $\begin{array}{l}1 \\
\text { est/2 } \\
\text { viv }\end{array}$ & $\begin{array}{l}1 \\
\text { est/2 } \\
\text { viv }\end{array}$ \\
\hline
\end{tabular}

Cuadro 2. Resumen de modificaciones aplicadas al Plan Regulador Comunal de Santiago. Fuente: elaboración propia (2013) en base a Ordenanzas Locales.

La utilización de esta flexibilidad se permite cumpliendo las exigencias de: a) construir un mínimo de $65 \%$ de departamentos con superficies útiles superiores o iguales a $50 \mathrm{~m} 2$, b) destinar el $40 \%$ de la superficie restante de la aplicación de la de ocupación de suelo para jardines, y c) se deberá contemplar un mínimo de vanos, equivalente al $30 \%$ de la superficie de la fachada que enfrenta la calle, en primer piso. Estos pisos adicionales, deberán estar distanciados de la línea oficial y/o edificación en $3 \mathrm{~m}$ como mínimo.

El caso específico del Edificio Isabel Plaza, correspondiente a la inmobiliaria ABSAL, una de las cuatro inmobiliarias que concentran el $48 \%$ de la superficie producida en la zona Santa Isabel la última década $(561.501 \mathrm{~m} 2)$. Al igual que la quinta parte de los proyectos realizados durante ese periodo, este proyecto ingreso a DOM pocos meses después de la modificación normativa permisiva que derogó el Seccional Santa Isabel, abriendo la zona a la libre operación del mercado inmobiliario, principalmente sin estrictos límites de superficie predial que este seccional consideraba. 

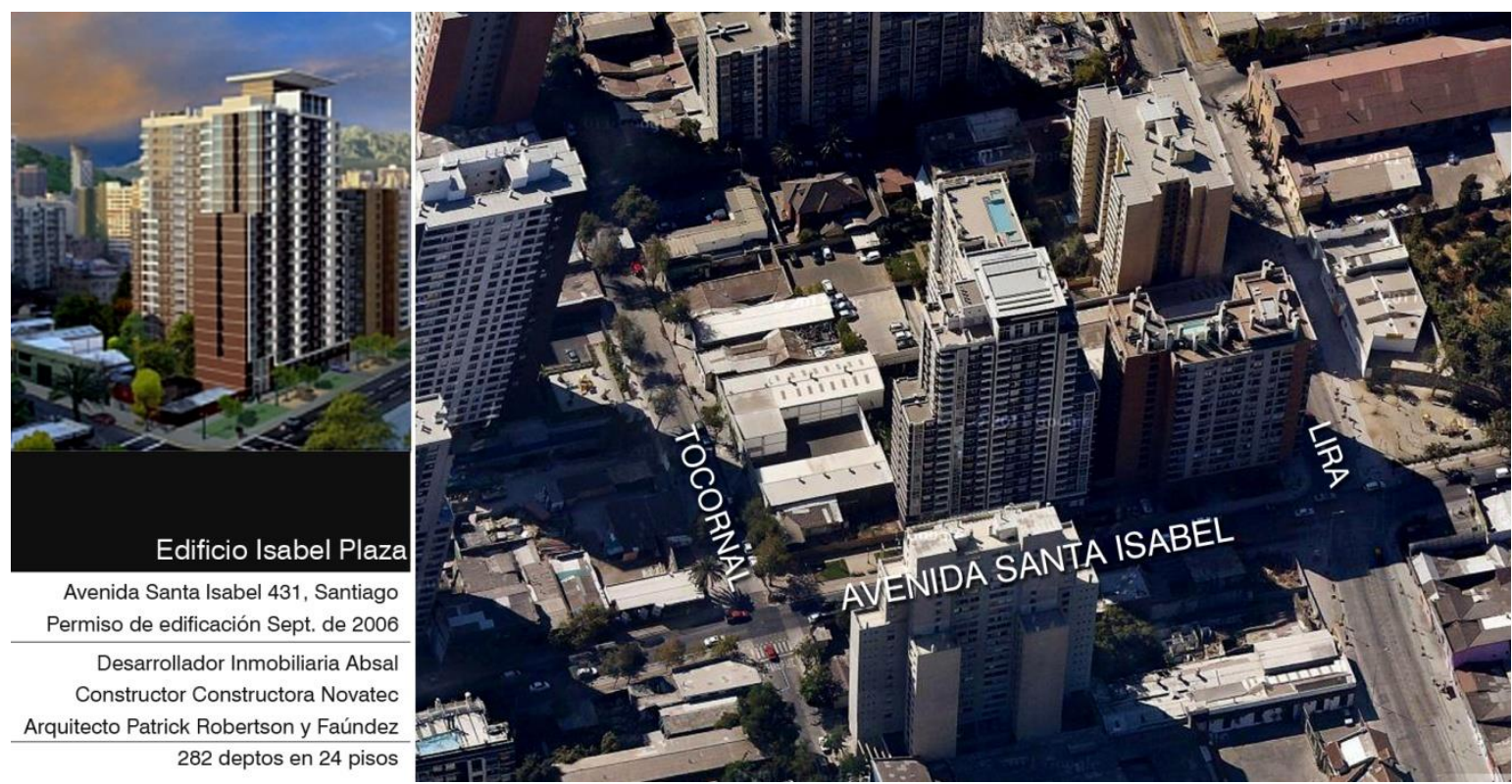

Figura 8. Caso Combinado. Edificio Isabel Plaza, comuna de Santiago. Fuente: Elaboración propia.

Si bien, el caso particular del Edificio Isabel Plaza está localizado en una subzona del seccional Santa Isabel (subzona B1c) considera un límite exigente de altura, al no considerar la posibilidad de construir edificación aislada sobre continua, a diferencia de estas zonas sí esposible generar construcciones en predios bajo los 5.000 o $2.000 \mathrm{~m}^{2}$. En concreto, el caso del Edificio Isabel Plaza, materializado en 24 pisos, sólo podría haber alcanzado los 14 pisos de edificación continua que actualmente tiene y no los 10 pisos en edificación aislada que suma. En tanto, la situación actual entrega la posibilidad de construir sobre la propia norma de plan regulador (que corresponde a 9 pisos) otros 4 pisos, alcanzando una altura máxima de 13 pisos.

La Figura 9 gráfica estas variaciones posibles. En primer lugar (primera barra) previo a 2006 con el Seccional Santa Isabel, esta edificación podría haber materializado un estimado de 180 de los 282 departamentos que finalmente fueron construido (segunda barra). Esta situación permitió aumentar la utilidad inmobiliaria en un $60 \%$ (de un estimado de 62 mil a casi 99mil). En un segundo escenario simulado (tercera barra), la renta obtenible baja considerablemente, casi equivalente a la primera simulación. Si bien en la actualidad es posible construir incluso un piso menos que la primera simulación, el proyecto tendría que cumplir con el requisito de aumentar la cantidad de departamentos mayores a $50 \mathrm{~m} 2$ de un $33 \%$ (construido) a un 65\% (hoy requisito para tener el beneficio de 4 pisos). Por lo mismo, la segunda simulación (tercera barra) adquiere una renta incluso mayor que la primera, al considerar que los precios de oferta de estos departamentos de más de $50 \mathrm{~m} 2$ es mayor (28,7 y 33,6 UF/m2 de superficie útil). 


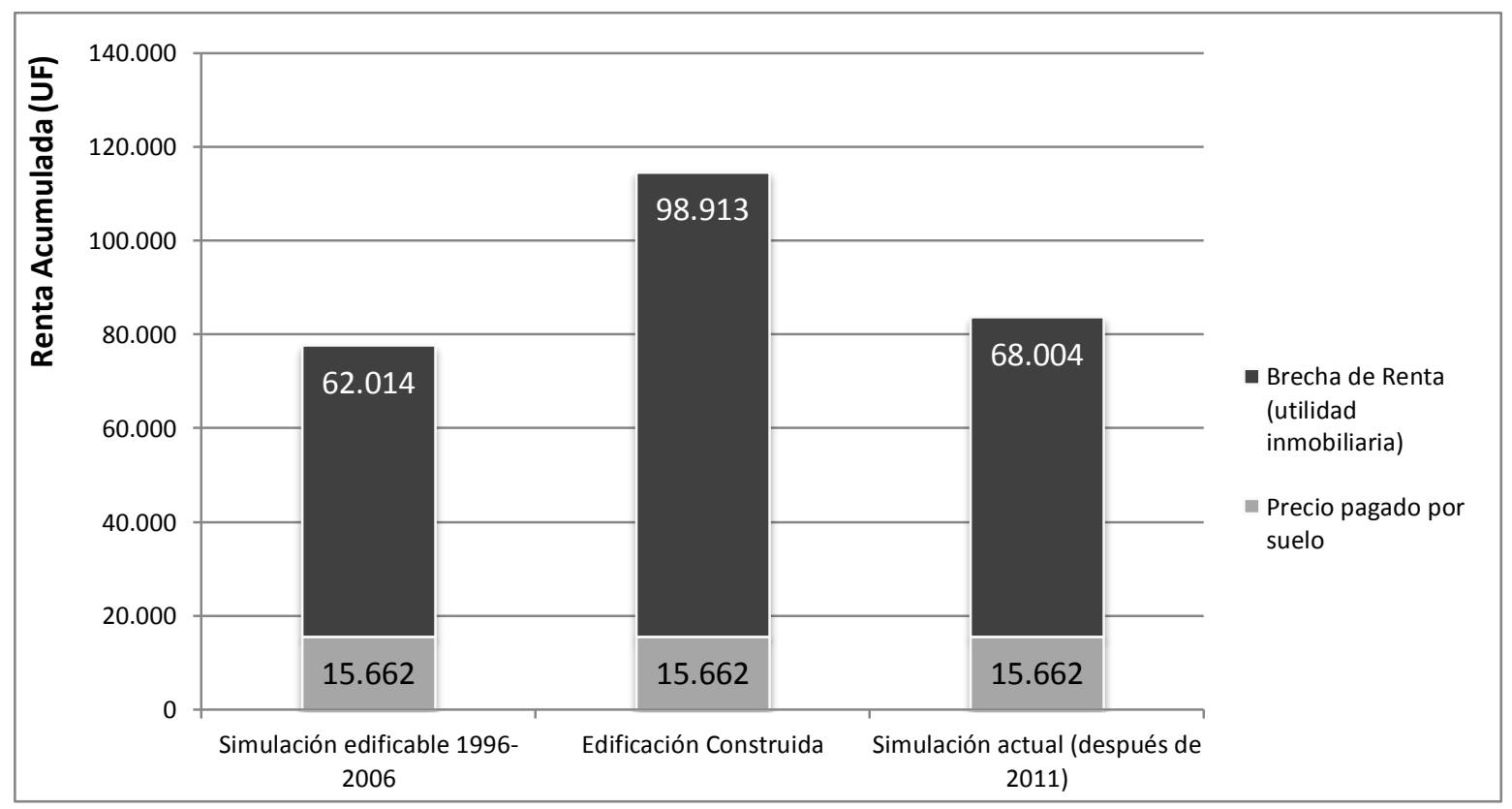

Figura 9. Gráfico de comparación de la renta inmobiliaria (RSC-2) y el precio pagado por el suelo (RCS-1) para las tres situaciones. Fuente: Elaboración propia.

\section{Conclusiones}

Los municipios del peri-centro del Gran Santiago han marcado su agenda urbana en base a distintas modificaciones a sus planes reguladores, con motivo de atraer la inversión inmobiliaria de renovación urbana en altura, cual es la forma dominante de producir ciudad en las metrópolis y algunas entidades intermedias chilenas. Desde los 2000' se han ido sumando comunas a este esquema pro-empresarialista iniciado por el municipio de Santiago, y signado por el rol que juega el sector público en el establecimiento de reglas, normas $y$, en algunos casos, disposiciones físico-ambientales para la operación del capital privado.

Particularmente, este artículo expone distintas modalidades mediante las cuales los municipios logran ajustar sus instrumentos de planificación coherente al proceso de renovación urbana privada. Se tiende a pensar, de manera generalizada, que la administración municipal es siempre "permisiva" o liberalizadora con el desarrollo inmobiliario, lo cual, si bien es meridianamente cierto, debe ser matizado y/o complejizado en base a las distinciones que aquí se han realizado. En cierto medida, los municipios establecer normativas "permisivas" para atraer inversión inmobiliaria, pero también existen ajustes normativos de carácter "flexible" y "dirigido". Incluso en el caso de la zona de Santa Isabel, comuna de Santiago, lo que se observa es la combinación de ajustes permisivos, flexibles y dirigidos. En todos los casos presentados, en las comunas de Independencia, Recoleta, Ñuñoa y Santiago, se observa que dichos ajustes normativos permiten una ampliación del volumen de 
construcción y, consecuentemente, una mayor utilidad inmobiliaria extraída de cada proyecto, con altos niveles de captura de renta de suelo urbano.

En el caso de los ajustes flexibles, lo que se ha visto es que los municipios entregan determinados incentivos y condiciones de excepción para que los desarrolladores inmobiliarios amplíen su volumen de construcción, resolviendo problemas morfológicos o, incluso, estableciendo ciertas "funciones sociales" en términos de ofrecer determinadas tipologías de vivienda y así responder, a grandes rasgos, a algunos objetivos municipales. Es así como, por ejemplo, el municipio de Santiago logró incentivar la construcción de unidades de vivienda sobre $50 \mathrm{~m}^{2}$, permitiendo colar objetivos públicos en proyectos privados.

Por su parte, los ajustes dirigidos han sido tal vez el resultado más importante que se expone en este artículo, ya que ha sido poco debatido el rol que tienen los planes reguladores en la exclusión deliberada de determinados tipos de desarrollo inmobiliario. Como se muestra en Ñuñoa y Santiago, estos municipios no solo entregan condiciones permisivas, sino que restringen operaciones menores, a través del establecimiento de superficies prediales mínimas y coeficientes de constructibilidad mínimos. Es notable observar que en 1996, mediante el seccional de Santa Isabel, el municipio de Santiago establece superficies mínimas de $2.000 \mathrm{~m}^{2}$ y hasta $5.000 \mathrm{~m}^{2}$ en algunos predios, situación extraordinariamente excluyente que luego es revocada cuando cambia el tipo de desarrollo en la zona. Cuando comienzan a aparecer inmobiliarias interesadas en proyectos más intensivos, de mayor altura sobre pequeños predios, el municipio cambia la normativa (derogando el seccional), permitiendo una nueva fase de desarrollo sobre predios en torno a las $1.000-1.500 \mathrm{~m}^{2}$. Por su parte, en el caso de Ñuñoa el municipio establece un coeficiente de constructibilidad mínimo de 2, que implica edificaciones de cuatro pisos mínimo, resultando una exclusión a las tipologías residenciales tradicionales de la zona. A saber, estos mecanismos de exclusión, que orientan las normativas a determinados productores con mayor capacidad de inversión, han sido denominados como formas de "redlining" por López Morales (2013b), en consistencia con investigaciones en ciudades anglo-americanas y europeas realizadas por Aalbers (2011).

De cierre, comentar que esta investigación debe abrirse a un campo de estudio más amplio, que incorpore la dimensión crítica de las relaciones de poder existentes entre los municipios y el sector inmobiliario privado, observando las específicas articulaciones e imbricación de intereses institucionales. No se trata solo de evaluar la manera en que las instituciones públicas facilitan las operaciones privadas sino que, de manera más ambiciosa, debe avanzarse hacia la comprensión de cómo se han entretejido, a diferentes escalas y niveles administrativos, los intereses públicos y privados en la renovación urbana del pericentro del Gran Santiago.

\section{Bibliografía}


AALBERS, M. (2011). M. Place, exclusion, and mortgage markets. Blackwell Publishing, U.K.

CATTANEO, R. (2011). Los fondos de inversión inmobiliaria y la producción privada de vivienda en Santiago de Chile. ¿Un nuevo paso hacia la financiarización de la ciudad? EURE, Vo.37, n¹12, pp.5-22.

CONTRERAS, Y. (2005). Dinámica inmobiliaria en el Programa de Repoblamiento: Un análisis a los efectos urbanos y sociales. Casos de Estudio: Barrios Brasil y Yungay. Tesis presentada al Instituto de Estudios Urbanos y Territoriales de la Pontificia Universidad Católica de Chile para optar al grado de Magíster en Desarrollo Urbano. Santiago.

CUENYA, B. Y CORRAL, M. (2011). Empresarialismo, economía del suelo y grandes proyectos urbanos: el modelo de Puerto Madero en Buenos Aires. EURE, Vo. 37, $\mathrm{n}^{\circ} 111$, pp. 25-45, Santiago.

DE MATTOS, C. (2006). Modernización capitalista y transformación metropolitana en América Latina: cinco tendencias constitutivas. En: GERAIGES DE LEMOS Amalia, Arroyo, M. y Silveira, M. L. (Eds.), Modernización capitalista y transformación metropolitana en América Latina: cinco tendencias constitutivas. (pp. 41-73). Sao Paulo: Consejo Latinoamericano de Ciencias Sociales.

DE MATTOS, C. (2007). Globalización, negocios inmobiliarios y transformación urbana. Nueva Sociedad (212), 82-96.

HACKWORTH, J. (2007). The neoliberal city: Governance, ideology, and development in American Urbanism. Cornell University Press.

HARVEY, D. (1989). From Managerialism to Entrepreneurialism: The Transformation in Urban Governance in Late Capitalism. Geografiska Annaler. Series B, Human Geography, 71(1), 3-17.

HERZER, H. (2008). Con el corazón mirando al sur. Transformaciones en el sur de la ciudad de Buenos Aires. Espacio Editorial, 2008, Buenos Aires.

I. MUNICIPALIDAD DE ÑUÑOA. (2003). Memoria Explicativa de la Modificación al Plan Regulador de la comuna de Ñuñoa.

I. MUNICIPALIDAD DE INDEPENDENCIA (2003). Memoria Explicativa de la Modificación al Plan Regulador de la comuna de Independencia.

JANOSCHKA, M., SEQUERA, J. y SALINAS, L. (2013). Gentrification in Spain and LatinAmerica - a Critical Dialogue. International Journal of Urban and Regional Research.

LÓPEZ MORALES, E (2013b). Urbanismo proempresarial y destrucción creativa: un estudio de caso de la estrategia de renovación urbana en el pericentro de Santiago de Chile, 1990-2005, Mexico: Infonavit-Redalyc. 
LÓPEZ MORALES, E. (2011). Gentrification by Ground Rent Dispossession: The Shadows Cast by Large Scale Urban Renewal in Santiago de Chile. International Journal of Urban and Regional Research 35(2).

LÓPEZ, E. (2009). Urban Entrepreneurialism and Creative Destruction: A Case-study of the Urban Renewal Strategy in the Peri-centre of Santiago de Chile, 1990-2005. Tesis para la obtención del PhD, The Bartlett Faculty of the Built Environment, University College London.

LÓPEZ, E., GASIC, I. Y MEZA, D. (2012). Urbanismo Pro-Empresarial en Chile: políticas y planificación de la producción residencial en altura en el pericentro del Gran Santiago. Revista INVI, 28 (76).

MONTECINOS, E. (2008). Descentralización y democracia en Chile: análisis sobre la participación ciudadana en el presupuesto participativo y el plan de desarrollo comunal. Revista de Ciencia Política, 26(2), 191-208.

NUISSL, H., HOHNKE, C., LUKAS, M., DURÁN, G. Y RODRIGUEZ, C. (2012). Megacity Governance: Concepts and Challenges. En Heinrichs et al. (eds.), Risk Habitat Megacity.

PECK \& TICKELL. (2002). Neoliberalizing space. En Brenner, N. \& Theodore, N. (Eds.) Spaces of Neoliberalism. Urban Restructuring in North America and Western Europe. Blackwell.

SHIN, H.B. (2009). Residential redevelopment and the Entrepreneurial Local State: The Implications of Beijing's Shifting Emphasis on Urban Redevelopment Policies. Urban Studies, 46(13), 2815-2839.

SMOLKA, M. Y AMBORSKI, D. (2003). Recuperación de plusvalías para el desarrollo urbano: una comparación inter-americana. EURE, 29(88), 55-77.

TORRES, M. (2006). Recuperación de la renta urbana: una tarea ética pendiente. Revista INVI No 58, Volumen 21: 42 a 70. Disponible en: http://revistainvi.uchile.cl/index.php/INVI/article/view/298/913

VICUÑA, M. (2013). El marco regulatorio en el contexto de la gestión empresarialista y la mercantilización del desarrollo urbano del Gran Santiago, Chile. Revista INVI, Vo. 28, No 78. [Consultado el 02-10-13] Disponible en: http://revistainvi.uchile.cl/index.php/INVI/article/view/761/1100

WARD, K. (2003). Entrepreneurial urbanism, state restructuring and civilizing 'New' East Manchester. Area - London, 35(2), 116-128.

ZUNINO, H. (2001). La planificación urbana en el Chile de hoy: -Actores sociales estructurados\|l y la construcción de redes de gobernabilidad. Revista de Geografía Norte Grande, 28: 73-78, Santiago. 